\title{
Polycystic Disease of Kidneys and Liver Presenting in Childhood
}

\author{
HELEN BLYTH and BARBARA G. OCKENDEN*
}

\begin{abstract}
From the Medical Research Council Clinical Genetics Unit, and Department of Morbid Anatomy, Institute of Child Health, 30 Guilford Street, London WC1
\end{abstract}

In congenital cystic malformations of the kidney, as in other groups of disorders, the accuracy of genetic counselling depends upon exact diagnosis. This requires the breakdown of the main heterogeneous group into specific entities, each of which is homogeneous from the genetic viewpoint and therefore carries a predictable recurrence risk within the family. It is particularly important to recognize the group of 'wholly genetically determined' conditions, those due to chromosomal and single gene mutations, since these may be associated with high risks for sibs or children of index patients.

The subject of the present study is 'true polycystic disease of the kidneys' as defined from the pathological viewpoint by Kissane (1966). In this group, two entities were already well established when the present survey was begun, and a possible third was emerging.

The first entity to be established was the dominantly inherited adult form of polycystic disease of the kidneys. This was recognized as an hereditary trait at least as early as $I 899$ by Steiner, and its manifestations in adults have been well described from the clinical, pathological, and genetic viewpoints (Oppenheimer, 1934; Fergusson, 1949; Dalgaard, 1957; Heggö, 1966). It is noteworthy that necropsy series agree that in about one third of the patients with this form of the disease there is associated localized cystic malformation of the liver. Although so well defined in adults, the occurrence of this adult type in children had been recorded only rarely and usually without pathological detail or illustration (Steiner, 1899; Halbertsma, 1932; Savera, 1946; Fergusson, 1949).

The second type of polycystic malformation of

Received 11 February 1971.

* Present address: Department of Pathology, North Staffordshire Royal Infirmary, Princes Road, Hartshill, Stoke-on-Trent, Staffordshire.

1-J.M.G. 257 the kidneys to be established is limited to children of the perinatal age group. This type is always associated with specific hepatic lesions, and is not recorded as occurring in the same family as the adult form. The family pattern is consistent with autosomal recessive inheritance (Lundin and Olow, 1961; Osathanondh and Potter, 1964a; Heggö and Natvig, 1965b).

A presumptive further entity was 'congenital hepatic fibrosis' with cystic kidneys. It was recognized that this association could occur in two or more sibs in a family (Kerr et al, 1961; Kerr, Warrick, and Hart-Mercer, 1962) but, in contrast to the first two entities described, no uniform clinical-pathological pattern had emerged for this third group. Even the term 'congenital hepatic fibrosis' was ill defined and some reports obviously included more than one pathological type. Hitherto the uncertainty concerning this third group was expressed by Kissane (1966): 'it is not possible at present to decide whether congenital hepatic fibrosis belongs among extrarenal lesions associated with renal polycystic disease or is an unrelated pleiotropic hereditary disorder, one manifestation of which may be cysts in the kidneys'. In addition, the literature included reports of occasional families with two or more sibs affected with true polycystic disease of the kidneys which came intermediate between the severe perinatal form and the form occurring with 'congenital hepatic fibrosis'. Lightwood and Loots (1932) recorded one such family. Other workers obviously aware of these intermediate types included Gwinn and Landing (1968). In defining the severe type of disease, which they called infantile polycystic disease of kidneys and liver' (rightly stressing the importance of the associated hepatic lesion) they noted that, while most children with this form die in infancy, there may be the occasional survivor.

The present study confirms the occurrence of the first entity, the adult dominant form of polycystic 
disease in children. The second entity, the severe perinatal form of polycystic disease is also confirmed. Further, this severe form is shown to represent one extreme in a series of entities which share qualitatively similar, though quantitatively varying, patterns of renal and hepatic malformation. It is shown how this concept can account both for the group of 'congenital hepatic fibrosis' with cystic kidneys and those intermediate familial cases which could not previously be classified.

In the past, a variety of other types of cystic kidney have been confused with true polycystic disease, particularly in the newborn, and these have been excluded from the present series. The most numerous of these are the cystic dysplastic group, including unilateral cystic dysplastic kidney-the commonest cystic renal disorder in childhood (Kissane, 1966)-and cystic kidneys in association with lower urinary tract obstruction. For this large group there is little evidence of genetic determination and this also probably applies to single and multilocular renal cysts.

Also excluded from the series are the rarer types of renal cystic malformation which may occur as one feature of wholly genetically determined syndromes. Examples of chromosome anomalies in which cystic kidneys may occur include Patau's and Edwards' syndromes (Osathanondh and Potter, 1964b; Taylor, 1968). In such instances there is little risk to sibs unless the effective trisomy results from a balanced translocation in one or other parent. Single gene determined conditions include tuberose sclerosis-an autosomal dominant disorder (Debré et al, 1952; Cree, 1969)—and oral-facialdigital syndrome, which is probably an X-linked condition lethal in males (Doege et al, 1964; Tucker et al, 1966). Further, at least two conditions which are possibly autosomal recessive are represented in the heterogeneous group of central nervous system malformations associated with cystic kidneys. The first is Gruber's syndrome, reviewed by Opitz and Howe (1969), who prefer the term Meckel's syndrome; the second is the association of cystic kidneys with the Dandy-Walker malformation of the brain (D'Agostino et al, 1963). The Zellweger syndrome (reviewed by Opitz et al, 1969) is another probably recessive syndrome in which cysts have regularly been found in the kidneys.

Single gene determined entities may also be represented in the heterogeneous group of renal cystic disorders which are characterized by medullary cysts. One severe form has been described in sibs (Handa and Tennant, 1968); this form has been equated with Fanconi's recessive juvenile nephronophthisis (Mongeau and Worthen, 1967; Pedreira,
Marmer, and Bergstrom, 1968) but this identification is by no means proven. A milder form compatible with dominant inheritance occurred in the large kindred recorded by Goldman et al (1966). 'Medullary sponge kidney' (Abeshouse and Abeshouse, 1960) is another entity, and has only rarely been described in more than one member of a family (see the review by Pennisi and Bunts, 1960; also Copping, 1967).

The present survey was undertaken because of confusion in the past between the many types of renal cystic disorder, and because genetic counselling had proved difficult in the case of a child with cystic disease of the kidneys who did not fit into any of the recognized genetic groups. It was hoped that, by studying an unselected series of patients admitted to a children's hospital and their families, it would be possible to define the different forms of true polycystic disease which occur in childhood, and the clinical and pathological criteria by which they may be recognized.

\section{Methods}

The subjects of this study were patients admitted to The Hospital for Sick Children, Great Ormond Street, and from families attending the genetic clinic at the same hospital.

The hospital patients were ascertained in one or more different ways. (1) By means of the surgical histology and post-mortem register of the Department of Morbid? Anatomy from 1948 to 1967 (inclusive). (2) Via the coding system of the Medical Records Department since its inception in 1951. (3) By direct notification from members of the hospital staff who had a special interest in renal disease. (4) Cases already known to one of the authors, a member of the Department of Morbid Anatomy.

In both the pathology registers and the medical records, cases were sought under a wide variety of categories to overcome differences in nomenclature adopted over the years; these included 'cystic kidney', 'multicystic kidney', 'polycystic kidney', 'cystic liver', 'fibrosis of the liver', 'cirrhosis of the liver' etc. It was decided to include as index patients only those cases with histological material available for examination; patients diagnosed on clinical or radiological grounds alone were not included in the study. One patient found in this way who subsequently died at another hospital was included in the study since, following her death, necropsy material was sent to the authors.

Going through the surgical specimen and post-mortem records, it was possible immediately to reject certain types of cystic malformation of the kidneys and cirrhosis or fibrosis of the liver on the basis of the histological descriptions and accompanying case summaries, or after reference to the clinical case notes. Thus, cases of cystic dysplastic kidneys and cases with cystic kidneys as one feature of a recognized syndrome were excluded. 
Similarly, cases of cirrhosis or fibrosis of the liver following neonatal hepatitis or associated with biliary atresia, and those secondary to a known disease, such as Wilson's or glycogen storage disease, were all rejected at this stage.

There remained 75 cases of cystic malformation of the kidneys or fibrosis or cirrhosis of the liver which could not immediately be allocated to one of these recognized groups or entities. In each case, the available sections were examined and the case was only retained if the pathological findings in the kidneys and/or liver conformed to, or resembled, a certain pattern which will be described later. Thirty-seven cases of cystic disease of the kidneys which were considered to be unlike the required pattern, and 21 cases of atypical fibrosis or cirrhosis of the liver without malformation of the bile ducts were eliminated in this way. Of the 17 cases which remained, 15 showed the specific pattern of renal and/or hepatic involvement required (see Results, section $A$ ) and in 2 cases the renal lesion resembled the required pattern but was not typical of it (see Results, section B). These 17 cases, who comprise the 'hospital index patients' belonged to 16 different families.

The families from the genetic clinic were traced from the disease index for the clinic. This index was started in 1957 and the search was made through the years 1957-1967. Here, all families registered under 'diseases of kidney' and 'diseases of liver' were traced, but only those in whom the diagnosis was that of cystic disease of the kidneys or of primary liver disorder were reviewed further. Of the 17 families traced in this way, 2 were already included in the hospital series having been selected by means of the pathology records, leaving a total of 15 new families for review. As with the hospital series, it was decided to include only those families in which the diagnosis could be confirmed histologically by the authors in at least one member, usually on specimens supplied by colleagues from other hospitals. This meant the elimination of 7 families: one could not be traced; histological sections were not available for 3 families; and in 3 other families review of the kidney sections showed the pattern of renal cystic disorder to be other than that specified by the authors. In the remaining 8 families, histological assessment showed that in 6 families ( 10 patients assessed) the kidney and/or liver abnormalities conformed to the pattern required (see Results, section A) and in 2 families (2 patients and 2 fetuses assessed) the renal lesion, while somewhat resembling the required pattern, was not typical (see Results, section B). These 8 families comprise the 'genetic clinic families' in the present series and, in them 12 full-term children and 2 fetuses have been examined histologically by the authors.

The total series of 29 patients assessed in 24 families is summarized in Table $\mathrm{I}$.

TABLE I

SOURCES OF THE 29 PATIENTS ASSESSED HISTOLOGICALLY

\begin{tabular}{l|l|c}
\hline & No. of Patients & No. of Families \\
\hline Hospital series & 17 & 16 \\
Genetic clinic series & $12(+2$ fetuses $)$ & 8 \\
\hline Total & $29(+2$ fetuses $)$ & 24 \\
\hline
\end{tabular}

With one exception (family 16), the parents in each family were interviewed either at home or at The Hospital for Sick Children, Great Ormond Street, and the family history obtained. In family 16 the parents had separated, the family doctor advised against any approach to them, and he kindly provided the sibship details in this family.

\section{Results}

\section{A. Childhood Type of Polycystic Disease of Kidneys and Liver}

The 15 children in the hospital series and 10 children from the genetic clinic families in whom the required pattern of kidney and liver lesions was

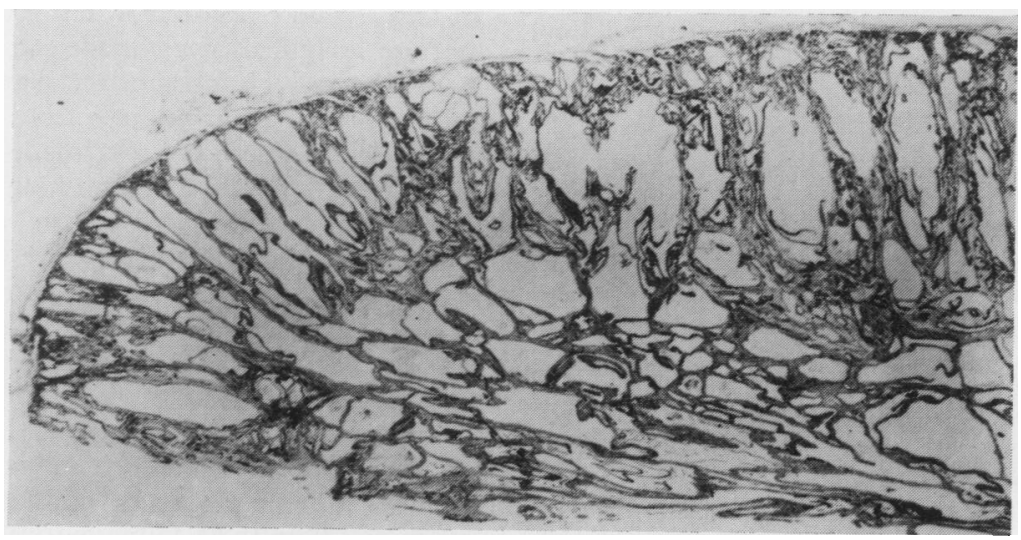

FIG. 1. Family 1, case 1. Microphotograph of kidney showing characteristic tubular dilatation. (Haematoxylin and eosin $\times 4 \cdot 5$.) 
found are considered first; the four remaining children in the series are discussed below (Results, section $B$ ). At the start of this study one of the authors (B.G.O.) was already familiar with this pattern as it occurs in the perinatal age group. It had been well described (Osathanondh and Potter, 1964a; Heggö and Natvig, 1965a and b; Kissane, 1966; and others) and had been encountered in patients outside the present hospital experience. The pattern of renal and hepatic involvement, which was made the criterion in defining the index patients, is as follows.

(1) Renal lesion. Throughout both kidneys there is a uniform distribution of radially arranged fusiform cysts. These are produced by dilated distal and collecting tubules and are lined by cuboidal or low columnar epithelium. The glomeruli, intertubular tissue, calyces, pelves, ureters, and lower urinary tracts are normal (Fig. 1).

(2) Hepatic lesion. In the liver there is a bizarre infolding, proliferation, and dilatation of welldifferentiated portal bile ducts and ductules, associated with a variable degree of periportal fibrosis.

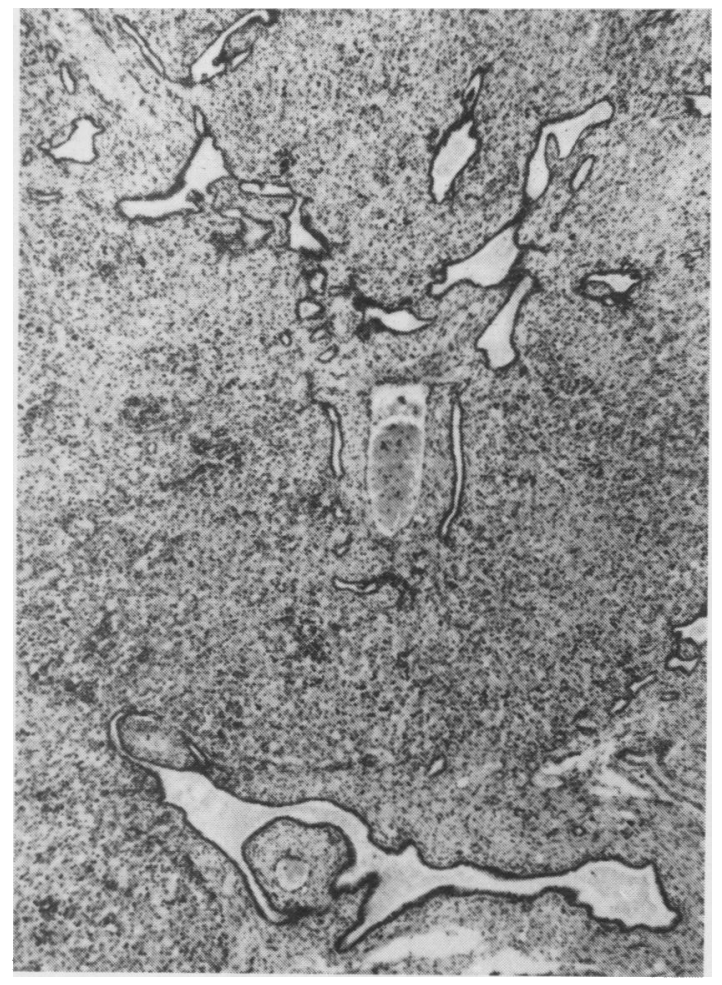

FIG. 2. Family 1, case 1. Microphotograph of liver showing characteristic bizarre proliferation and dilatation of bile ducts. $(\mathrm{H} \& \mathrm{E} \times 28$.)
The malformation affects all the portal triads and is uniformly distributed throughout the organ, the hepatic lobular architecture being well preserved (Fig. 2).

The association of these particular renal and hepatic lesions was found in children of all ages in the present series, though the extent of the lesions varied between one age group and another as will be described later. This very specific combination of kidney and liver malformations is therefore designated the 'Childhood type of polycystic disease of kidneys and liver'.

At the completion of the study (April, 1968), of the 25 children in the series with this Childhood type of polycystic disease, 18 were dead and 7 living. In making the histological diagnosis (see Table II) both renal and hepatic tissues were available in each of 20 cases, the material being post mortem in 14 (using the family numbers given in Table IV to VII, these were the first and third children in family 1 , first child in family 5 , and children in families $2,3,4,6,8,9,10,11,18$, and 19), and surgical biopsy in 6 (families $7,12,14,16$, and 17).

TABLE II

THE ORGANS EXAMINED HISTOLOGICALLY IN MAKING DIAGNOSIS OF CHILDHOOD TYPE OF THE DISEASE

\begin{tabular}{l|c|c|c|c}
\hline $\begin{array}{c}\text { Tissue Available } \\
\text { for Histology }\end{array}$ & \multicolumn{2}{|c|}{ Deceased Children } & $\begin{array}{c}\text { Living } \\
\text { Children }\end{array}$ & $\begin{array}{r}\text { Total } \\
\text { Children }\end{array}$ \\
\cline { 2 - 5 } & Necropsy & $\begin{array}{c}\text { Surgical } \\
\text { Biopsy }\end{array}$ & $\begin{array}{c}\text { Surgical } \\
\text { Biopsy }\end{array}$ & \\
\hline $\begin{array}{l}\text { Both kidney and } \\
\text { liver }\end{array}$ & 14 & 1 & 5 & 20 \\
$\begin{array}{l}\text { Kidney only } \\
\text { Liver only }\end{array}$ & 2 & - & -2 & 2 \\
\hline \multicolumn{1}{|c|}{ Totals } & 17 & 1 & 7 & 25 \\
\hline
\end{tabular}

In two (second children in families 1 and 5) postmortem diagnosis was made on renal histology alone, but in each instance sections of both kidneys and liver were available for a sib. In one case, the post-mortem diagnosis was made on hepatic histology alone (family 13): the kidneys of this child had been noted to be 'polycystic' at necropsy. In the remaining two cases, who are alive (families 15 and 20) the diagnosis was confirmed on hepatic biopsy only, but in both there was definite radiological evidence of renal cystic disease.

No cystic malformations of other organs were found in any of the cases examined.

Other congenital malformations identified were: pulmonary stenosis (second child in family 5), short left femur (family 6), talipes equinovarus (family 9), and left duplex kidney and ureterocoele (family 18). 
Clinical and Pathological Assessment of Patients. The 25 cases showing the childhood type of polycystic malformation of kidneys and liver were assessed individually, firstly, on the basis of the clinical findings, including age and mode of presentation and progress; and secondly, the pathological findings. The pathological assessment was two-fold in each case. In the kidneys an estimate was made of the proportion of renal tubules that were cystic, and in the liver the degree of both biliary malformation and periportal fibrosis were assessed. On the basis of either the clinical findings or the pathological assessment the 25 cases were found to fall into the same 4 contiguous groups. These were named after the age at presentation: (1) Perinatal (2) Neonatal (3) Infantile, and (4) Juvenile groups. The clinical and pathological findings in the 4 groups are summarized in Table III and further details are given below. In this table and Tables IV to VII, the families are numbered in alphabetical order of surname within each group.
Genetic Considerations. The 25 patients examined histologically by the authors, of whom 15 were hospital and 10 genetic clinic cases, belonged to 20 different families. On grouping the patients into the 4 groups-perinatal, neonatal, infantile, and juvenile-on clinico-pathological criteria, it was found that there was no overlap of these four groups within families; that is, within any given family all the children examined were found to fall into one and the same group.

\section{Description of the 4 Groups.}

1. Perinatal group (9 patients assessed in 6 families). Of the families included in this group, four were genetic clinic families and two were hospital families. Details of the sibships are given in Table IV.

All the children in this group presented at birth with very marked abdominal distension due to huge symmetrical renal masses. None of them survived to 6 weeks. Taking family 1 as an example, the parents had already lost two babies-both dying

TABLE III

SUMMARY OF THE CLINICO-PATHOLOGICAL FEATURES IN THE 4 GROUPS OF THE CHILDHOOD TYPE OF DISEASE

\begin{tabular}{|c|c|c|c|c|c|c|c|c|c|}
\hline \multirow[b]{3}{*}{ Group } & \multirow[b]{3}{*}{$\begin{array}{l}\text { Family } \\
\text { Numbers }\end{array}$} & \multirow[b]{3}{*}{$\begin{array}{l}\text { No. of } \\
\text { Cases } \\
\text { Ex- } \\
\text { amined }\end{array}$} & \multirow[b]{3}{*}{$\begin{array}{c}\text { Age at } \\
\text { Presentation* }\end{array}$} & \multirow[b]{3}{*}{$\begin{array}{c}\text { Mode of } \\
\text { Presentation }\end{array}$} & \multirow[b]{3}{*}{$\begin{array}{l}\text { Typical } \\
\text { Progress }\end{array}$} & \multirow[b]{3}{*}{ Survival Time* } & \multicolumn{3}{|c|}{ Pathology } \\
\hline & & & & & & & \multirow{2}{*}{$\begin{array}{c}\text { Kidneys } \\
\text { Proportion } \\
\text { of Dilated } \\
\text { Renal } \\
\text { Tubules }\end{array}$} & \multicolumn{2}{|c|}{ Liver } \\
\hline & & & & & & & & $\begin{array}{c}\text { Propor- } \\
\text { tion of } \\
\text { Dilated } \\
\text { and } \\
\text { Infolded } \\
\text { Bile Ducts }\end{array}$ & $\begin{array}{l}\text { Extent } \\
\text { of } \\
\text { Periportal } \\
\text { Fibrosis }\end{array}$ \\
\hline Perinatal & 1 to 6 & 9 & At birth & $\begin{array}{l}\text { Bilateral huge } \\
\text { renal masses }\end{array}$ & $\begin{array}{l}\text { Early decease } \\
\text { or rapid } \\
\text { progression } \\
\text { of uraemia } \\
\text { and death }\end{array}$ & $\begin{array}{l}1 \text { stillborn; } \\
6 \text { died }<\frac{1}{365} ; \\
2 \text { died }<\frac{6}{52}\end{array}$ & $\begin{array}{l}90 \% \text { or } \\
\text { more }\end{array}$ & $\underset{\text { affected }}{\text { All }}$ & Minimal \\
\hline Neonatal & 7 to 11 & 6 & $\frac{1}{365}-\frac{1}{12}$ & $\begin{array}{l}\text { Bilateral large } \\
\text { kidneys }\end{array}$ & $\begin{array}{l}\text { Progressive } \\
\text { renal } \\
\text { failure }\end{array}$ & $\begin{array}{l}3 \text { died }<\frac{6}{52} \\
2 \text { died }>\frac{6}{52}<1 \\
1 \text { alive at } \frac{8}{12}\end{array}$ & About $60 \%$ & $\begin{array}{l}\text { All } \\
\text { affected }\end{array}$ & Mild \\
\hline Infantile & 12 to 16 & 5 & $\frac{3}{12}-\frac{6}{12}$ & $\begin{array}{l}\text { Bilateral large } \\
\text { kidneys; } \\
\text { hepato- } \\
\text { splenome- } \\
\text { galy }\end{array}$ & $\begin{array}{l}\text { Chronic renal } \\
\text { failure; } \\
\text { systemic } \\
\text { and portal } \\
\text { hypertension }\end{array}$ & $\begin{array}{l}2 \text { died }<10 ; \\
3 \text { alive at } 1 \frac{1}{2}, 4 \text {, } \\
\text { and } 10\end{array}$ & About $25 \%$ & $\begin{array}{l}\text { All } \\
\text { affected }\end{array}$ & Moderate \\
\hline Juvenile & 17 to 20 & 5 & $\begin{array}{l}\frac{6}{52}(1 \text { child }) t \\
1-5(4 \text { children })\end{array}$ & Hepatomegaly & $\begin{array}{l}\text { Portal hyper- } \\
\text { tension, } \\
\text { often } \\
\text { necessitat- } \\
\text { ing } \\
\text { portocaval } \\
\text { shunt }\end{array}$ & $\begin{array}{l}1 \text { died at } \frac{9}{12} ; \dagger \\
1 \text { died at } 20 ; \\
3 \text { alive at }>12\end{array}$ & $\begin{array}{l}\text { Less than } \\
10 \%\end{array}$ & $\begin{array}{l}\text { All } \\
\text { affected }\end{array}$ & Gross \\
\hline
\end{tabular}

* In years or fractions of a year.

† This was the child in family 18 . Hepatic enlargement was found at $\frac{6}{52}$, when she was admitted to hospital with recurrent septicaemia and meningitis following umbilical sepsis. The liver remained large until her death at $\frac{9}{12}$. 
TABLE IV

DETAILS OF SIBSHIPS IN PERINATAL GROUP

\begin{tabular}{|c|c|c|c|c|}
\hline \multirow{2}{*}{$\begin{array}{l}\text { Family } \\
\text { No. }\end{array}$} & \multirow{2}{*}{$\begin{array}{l}\text { G } \\
\text { or } \\
\text { H }\end{array}$} & \multirow[t]{2}{*}{ Details of Sibships } & \multicolumn{2}{|c|}{$\begin{array}{l}\text { Parents' } \\
\text { Date of Birth }\end{array}$} \\
\hline & & & Mother & Father \\
\hline 1 & G & $\begin{array}{l}F^{\circ} \text {, born } 7 \cdot 57, \mathrm{~d}<1 \text { day; } F^{\circ}, 12 \cdot 65, \mathrm{~d}<1 \\
\text { day; } F, 4 \cdot 67, \mathrm{~d}<1 \text { day }\end{array}$ & $1 \cdot 31$ & $11 \cdot 25$ \\
\hline 2 & $\mathbf{H}$ & $M, 6.55 ; M, 5.60 ; M^{*} ; 3.66, d 1$ day & $3 \cdot 34$ & $2 \cdot 29$ \\
\hline 3 & G & F, $\mathrm{d}<1$ day, $1.64 ; F^{\bullet}$, SB 3.66 & $9 \cdot 39$ & $4 \cdot 36$ \\
\hline 4 & $\mathbf{H}$ & 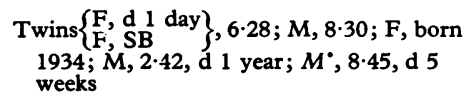 & $4 \cdot 04$ & $8 \cdot 04$ \\
\hline 5 & G & $\begin{array}{l}M^{*}, 11 \cdot 61, \mathrm{~d} \text { soon after birth; } F, 8.64, \mathrm{~d} \\
\text { soon after birth; } M: S B 10.66 \text { (macerated) }\end{array}$ & $3 \cdot 32$ & $5 \cdot 31$ \\
\hline 6 & G & $\mathrm{F}, 3.65 ; F^{\circ}, 10.67, \mathrm{~d} 23$ days; $\mathrm{F}, 12.68$ & $12 \cdot 37$ & $2 \cdot 35$ \\
\hline
\end{tabular}

Key to Tables IV-VII and IX. $G=$ genetic clinic series; $H=$ hospital series; $M=$ male; $\mathrm{F}=$ female; $\mathrm{U}=$ sex not known; $\mathrm{SB}=$ stillborn; $\mathrm{d}=\mathrm{died}^{{ }^{*}}=$ index patients in the hospital series and proven affected children born before referral in the genetic clinic series, all histologically confirmed. Italics indicate affected children.

In the genetic clinic series, all other children shown in italics were also assessed histologically by the authors. In the hospital series, affected children other than the index patients were not assessed histologically; reasons for considering them affected are given in the text.

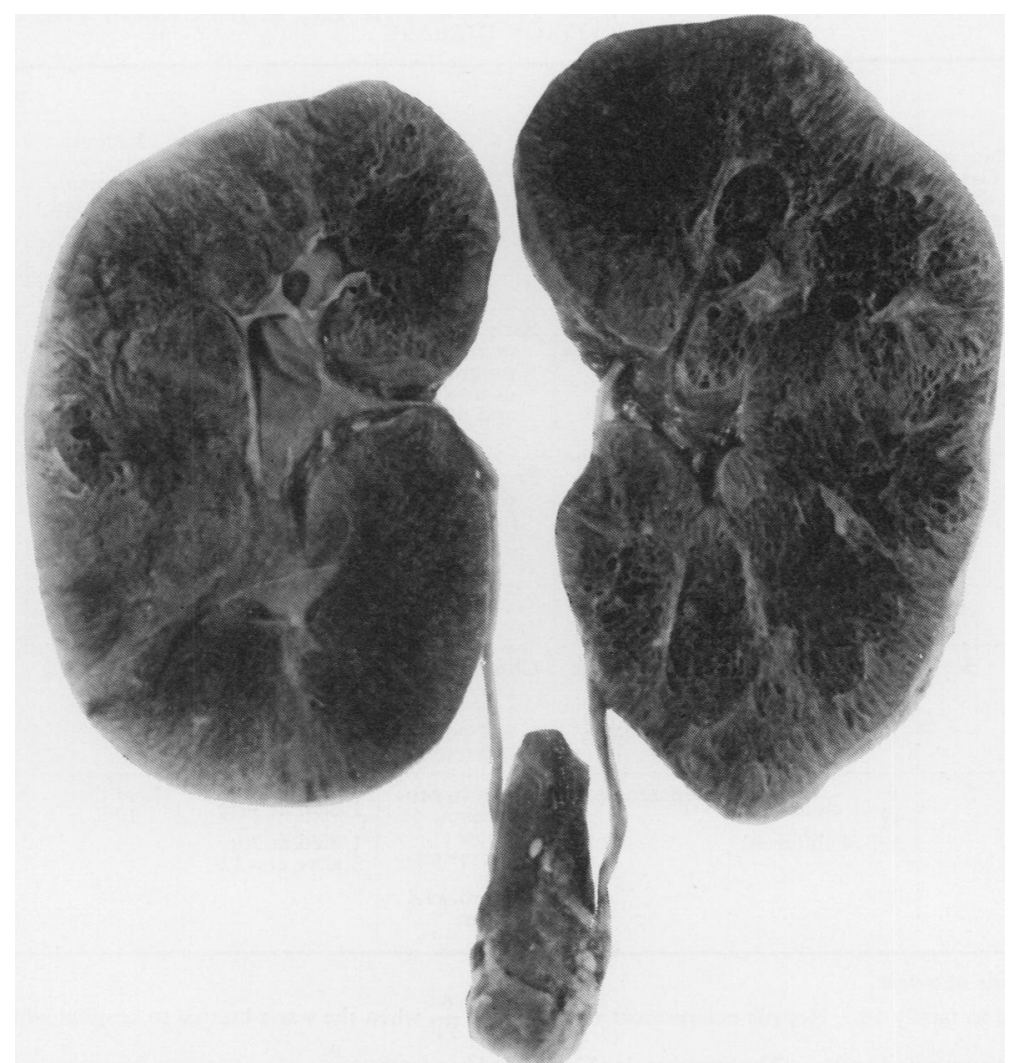

FIG. 3. Family 2. Macrophotograph of kidneys showing uniform enlargement due to radially arranged cystic tubules. ( $\times 1$.) 
soon after birth-when they were referred to the genetic clinic and given a 1 in 4 risk of recurrence. Subsequently a third affected child was born. The first baby was delivered by forceps for fetal distress, the other two by lower segment Caesarean section; the mother was sterilized at the time of the second abdominal operation. None of the infants survived for more than a few hours. In each case the necropsy showed gross bilateral renal enlargement with preservation of the normal reniform shape; the kidneys of one child were described as being larger than those of a normal adult. The cut surfaces showed that the enlargement was due to a uniform distribution of radially arranged elongated cystic tubules, with preservation of the corticomedullary pattern and normal pelves. The livers were noted to be normal in size, congested, and the cut surfaces were not apparently cystic. Sections of the kidneys of all three babies in family 1 were much alike; in each there was cystic malformation of 90 per cent or more of the tubules (Fig. 1). Sections of the liver were examined in the first and third children, and again the histological resemblance between the two was striking; all the bile ducts and ductules showed ectasia and there was minimal periportal fibrosis (Fig. 2). Macroscopic photographs of the kidneys and liver are not available for any of the children in this family, but the macroscopic appearances of the kidneys and liver in the child in family 2 are shown in Figs. 3 and 4, and the microscopic appearances in Figures $5 \mathrm{a}$ and $\mathrm{b}$ and 6.

The close similarity between the histological findings in the children in family 1 and the child in family 2 is shown in Figs. 1 and 5 and Figs. 2 and 6. In this first group, identical histological appearances were seen in the kidneys and liver in every case. The only difference was in the recorded macroscopic appearance of the liver. In each infant in family 1 ,

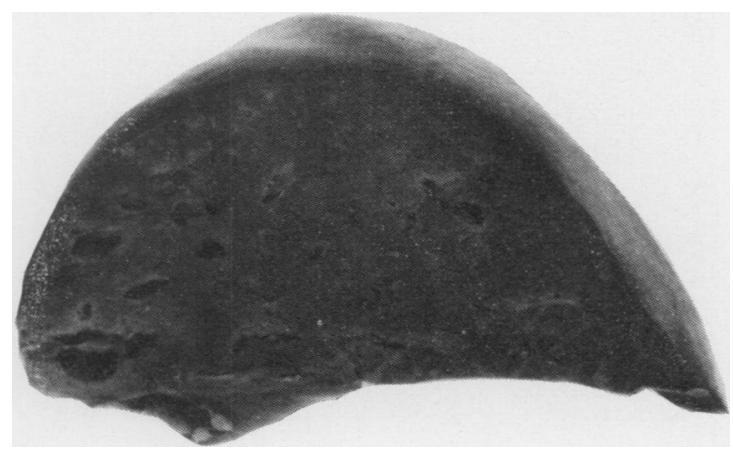

FIG. 4. Family 2. Macrophotograph of cut surface of liver showing fibrosis of portal tracts some of which contain biliary cysts. $(\times 1$.) it was noted that cysts were not seen, in the cases iu families 2 and 4 small cysts were noted, and in families 3, 5, and 6 there was no mention as to the presence or absence of liver cysts.

Considering now the 6 families represented in this group, in each of two families-family 1 (already described) and family 5-there was more than one affected child in the sibship. In addition to the patients examined there were 7 unaffected sibs of whom one, a boy in family 4 died at the age of one year but, according to the family doctor, 'did not have polycystic kidneys'. Four other children born into these families were either stillborn or died soon after birth. Two of them, in family 4, were premature twin girls, reported as being 'uniovular' (presumably on the basis of there being one placenta). These twins were both breech presentations; the first died at age one day, birth weight $2 \mathrm{lb}$; the second was stillborn, birth weight $2 \mathrm{lb} 3 \mathrm{oz}$ : there was no necropsy for either child. The child in family 3 who died 7 hours after birth was thought to have atelectasis, but again there was no necropsy. A necropsy was performed on the premature macerated male infant in family 5 and sections showed suspicious dilatation and elongation of the renal tubules bu autolysis had proceeded too far for a definite diag- -6 nosis to be made.

In family 5, both parents had normal intravenous pyelograms.

2. Neonatal group (6 patients assessed in 5 families). Of these families two were genetic clinic and three hospital families. Details of the sibships are given in Table $\mathrm{V}$.

The children in this group all presented within the first month of life with abdominal distension due to bilaterally enlarged kidneys. Five died before the age of 8 months from progressive renal failure, the one surviving child of the group was 8

TABLE V

DETAILS OF SIBSHIPS IN NEONATAL GROUP

\begin{tabular}{|c|c|c|c|c|}
\hline \multirow{2}{*}{$\begin{array}{l}\text { Family } \\
\text { No. }\end{array}$} & \multirow{2}{*}{$\begin{array}{l}\text { G } \\
\text { or } \\
\text { H }\end{array}$} & \multirow[t]{2}{*}{ Details of Sibships } & \multicolumn{2}{|c|}{$\begin{array}{c}\text { Parents' } \\
\text { Date of Birth }\end{array}$} \\
\hline & & & Mother & Father \\
\hline 7 & G & $M^{\bullet}, 7 \cdot 67$ & $3 \cdot 46$ & $9 \cdot 47$ \\
\hline 8 & $\mathbf{H}$ & $\begin{array}{l}\mathrm{F}, 56 ; M^{\circ}, 8.63, \mathrm{~d} 11 \text { days; } \\
\mathrm{F}, 9.64\end{array}$ & $12 \cdot 29$ & $2 \cdot 24$ \\
\hline 9 & $\mathbf{H}$ & $\begin{array}{l}\text { Miscarriage; } M, 5 \cdot 57 ; M^{\circ} \\
4.59 \text {, d } 5 \text { weeks; } F, 3 \cdot 60 \text {, } \\
\text { d } 5 \text { years } 10 \text { months; } M \text {, } \\
4.62 ; F, 7 \cdot 66, \mathrm{~d} 3 \text { months }\end{array}$ & $4 \cdot 31$ & $6 \cdot 25$ \\
\hline 10 & $\mathbf{H}$ & $\begin{array}{l}\mathrm{F}, 1 \cdot 37 ; \mathrm{F}, 2 \cdot 41 ; M^{\circ}, 5 \cdot 47, \mathrm{~d} 8 \\
\text { months; F, } 10.55\end{array}$ & $6 \cdot 12$ & $3 \cdot 07$ \\
\hline 11 & $\mathbf{G}$ & $\begin{array}{l}F^{*}, 4 \cdot 62 \text {, d } 5 \text { months; } M, 8 \cdot 63 \text {, } \\
\text { d } 1 \text { month }\end{array}$ & $5 \cdot 31$ & $10 \cdot 29$ \\
\hline
\end{tabular}




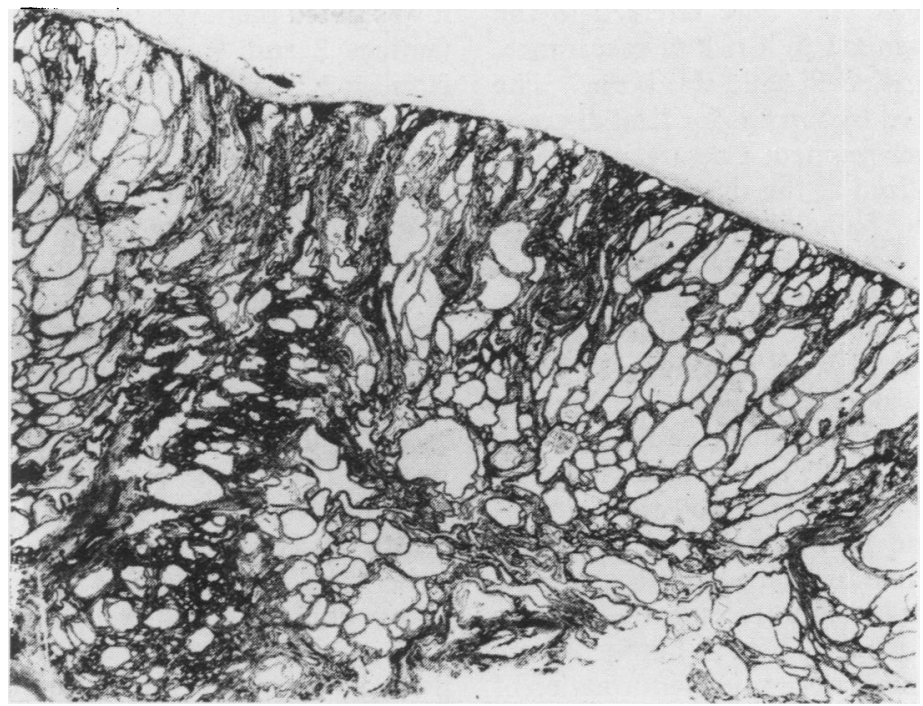

Fig. 5a. Family 2. Microphotograph of kidney, showing longitudinal dilatation of the majority of the tubules. $(\mathrm{H} \& \mathrm{E} \times 4.5$.

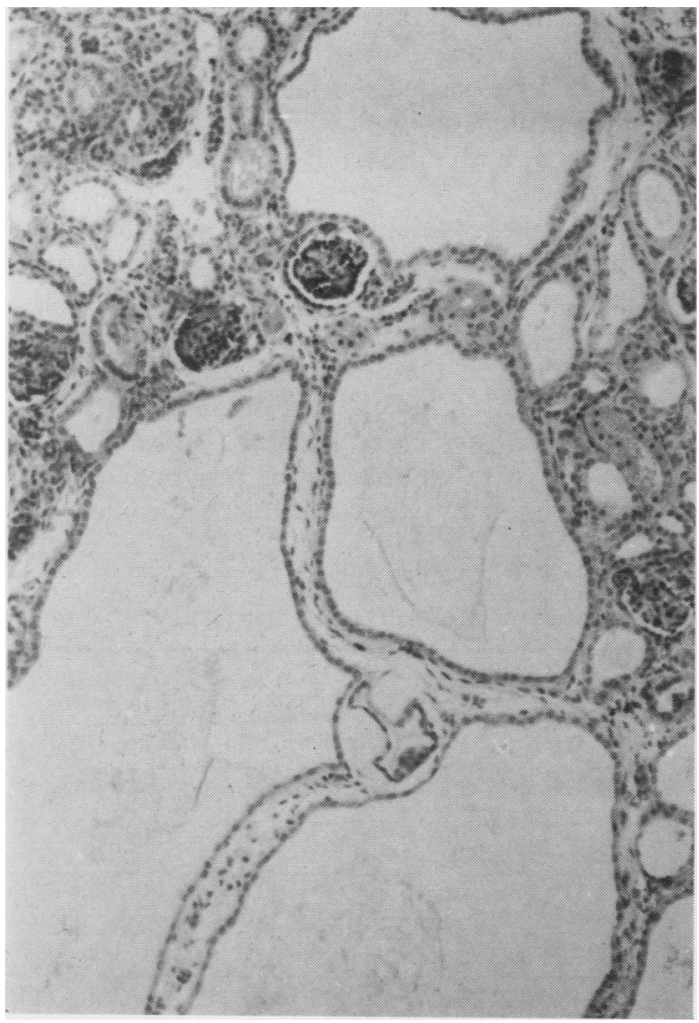

Fig. 5b. Family 2. Microphotograph of renal cortex, showing cystic tubules lined by cuboidal epithelium and adjacent normal glomeruli and convoluted tubules. (H \& E $\times 45$.)

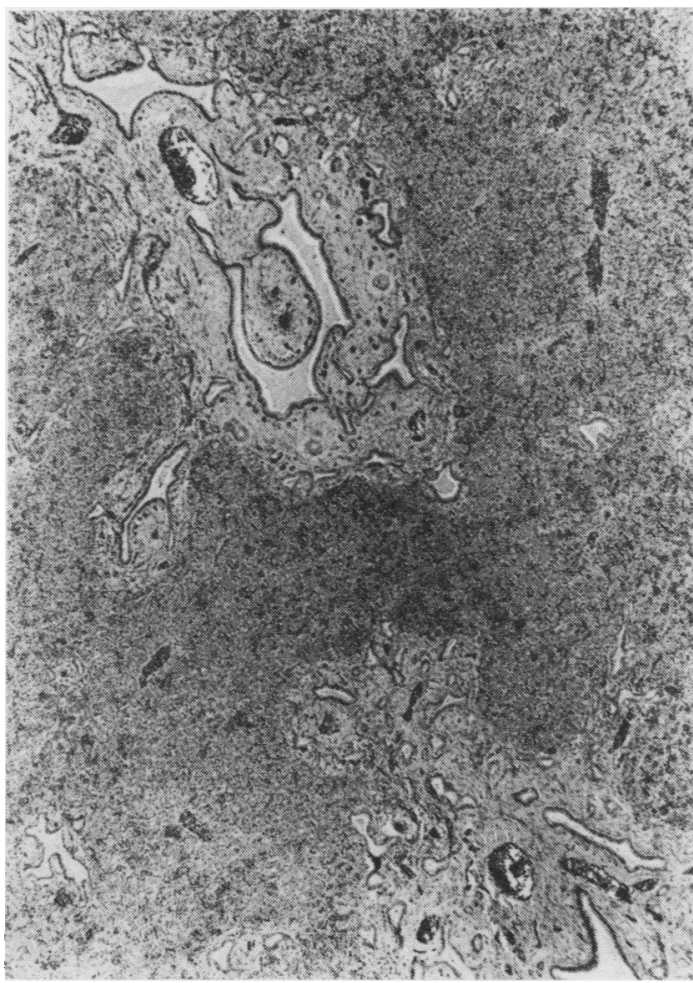

FIG. 6. Family 2. Microphotograph of liver showing bizarre proliferation of bile ducts in all portal tracts. (H\& E $\times 20$.)

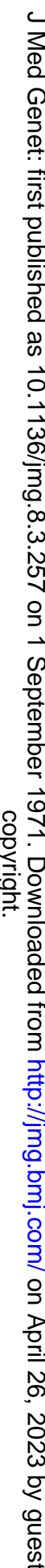

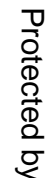




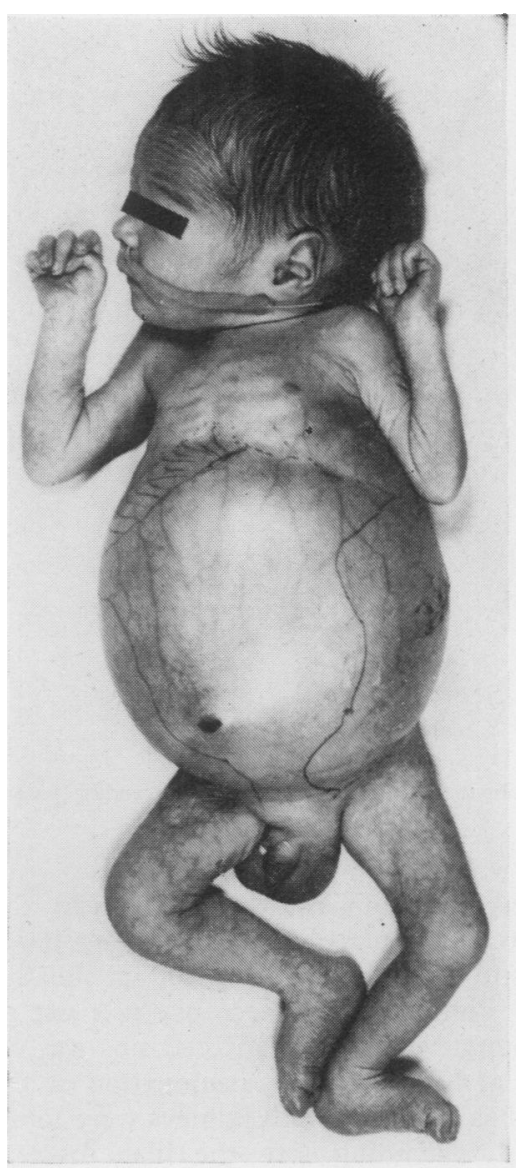

FIG. 7. Family 9 . Affected boy aged 3 weeks showing hepatic and renal enlargement.

months old on 31 March 1968 . Those who succumbed earliest probably did so because of pyelonephritis and/or cholangitis. The affected boy in family 9 is typical of the group as a whole: abdominal distension was noticed on the first day of life and examination revealed easily palpable kidneys. At 3 weeks he was oedematous with a very distended abdomen due to massive enlargement of both kidneys and hepatic enlargement (Fig. 7). Wedge biopsy of the left kidney at age one month confirmed the clinical diagnosis of polycystic disease of the kidneys and liver. His progress was steadily downhill with a rising blood urea and increasing dyspnoea. He died at age 5 weeks, the terminal blood urea being over $300 \mathrm{mg} / 100 \mathrm{ml}$. Necropsy showed polycystic disease of the kidneys with superimposed acute pyelonephritis, polycystic disease of the liver, and left ventricular hypertrophy due to hypertension. The kidneys weighed $434 \mathrm{~g}$ (right) and $400 \mathrm{~g}$ (left). On bisection they were entirely cystic, some of the cysts containing purulent material (Fig. 8). The pelves, ureters and bladder were normal. Microscopically about $60 \mathrm{per}$ cent of the renal tubules were dilated (about 1 in 5 grossly, and of the rest about 1 in 2 moderately). Foci of acute pyelonephritis were seen (Fig. 9). The liver weighed $252 \mathrm{~g}$, was brown in colour, of firm consistency, and mottled. Bisection revealed several cystic portal areas scattered diffusely throughout both lobes; the cysts were thin walled and contained apparently clear fluid (Fig. 10). Microscopically, all the intrahepatic bile ducts were abnormal; the larger ducts were enormously dilated and serpiginous, and the smaller ducts and ductules were moderately increased in number and also serpiginous. There was mild portal fibrosis and cholangitis (Fig. 11).

In this group of 5 families, in addition to the patients examined-which included the affected boy

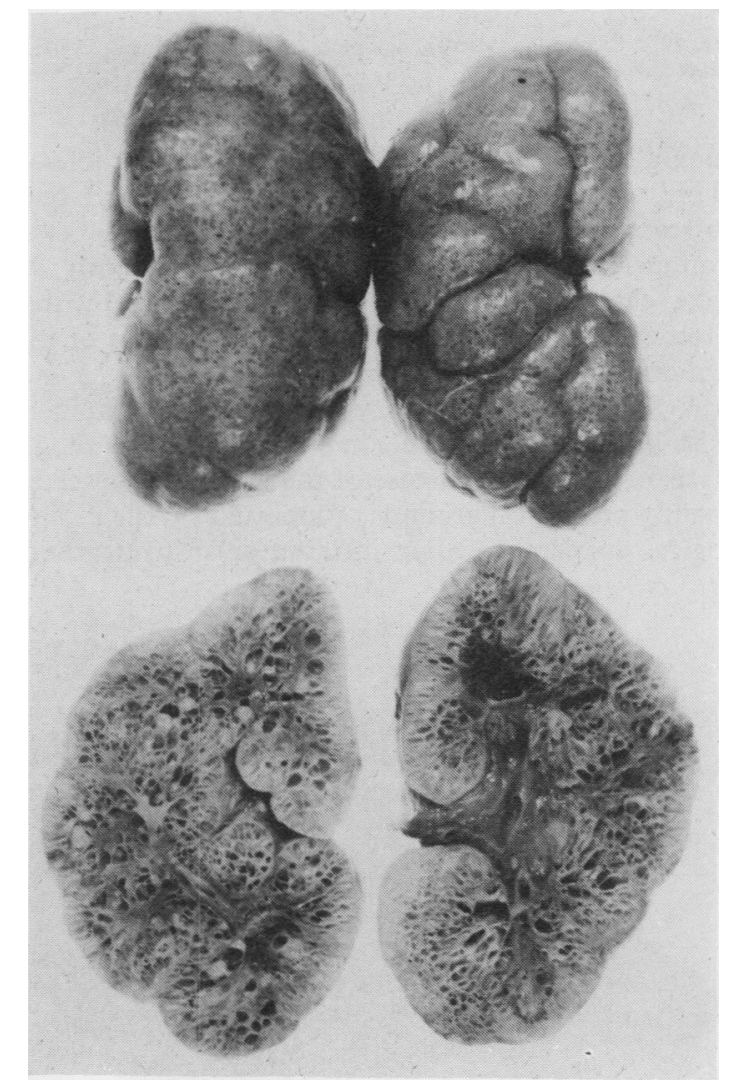

FIG. 8. Family 9. Macrophotograph of kidneys showing fetal lobulation and enlargement by fusiform cystically dilated tubules (Reduced $\times\{$. $)$ 


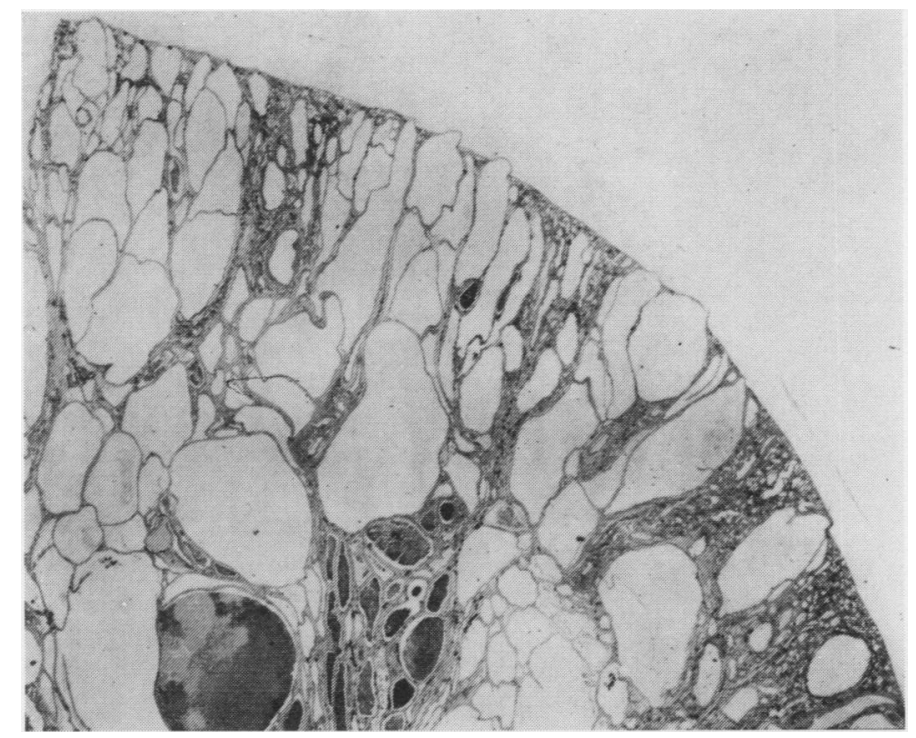

Fig. 9. Family 9. Microphotograph of kidney showing cystic dilatation of about $60 \%$ of the tubules and ascending pyelonephritis $(\mathrm{H} \& \mathrm{E} \times 4 \cdot 5$.

in family 11 born after referral to the genetic clinicthere were 2 affected sibs, 7 unaffected, and one miscarriage. The two affected sibs were two younger sisters of the index patient in family 9. The elder of these 2 children was noted by the mother to have abdominal enlargement from birth. On examination at another hospital at 7 months she was found to have a very protruberant abdomen with hard masses palpable in both loins. The diagnosis of polycystic disease of the kidneys was made mainly on clinical grounds, supported by the radiological appearance after intramuscular pyelogram.
She died in uraemia at 5 years 10 months, the blood urea having risen steadily from $72 \mathrm{mg} / 100 \mathrm{ml}$ at 70 months to more than $500 \mathrm{mg} / 100 \mathrm{ml}$ shortly before death. Permission for necropsy was not granted. The younger of the two affected sibs was very distressed at birth, and on examination at the same hospital as her sister both kidneys were found to be enlarged, extending into the iliac fossae. At 3 weeks of age the blood urea was $85 \mathrm{mg} / 100 \mathrm{ml}$; she gradually developed signs of uraemia and died suddenly at home at 3 months. Again no necropsy was permitted.

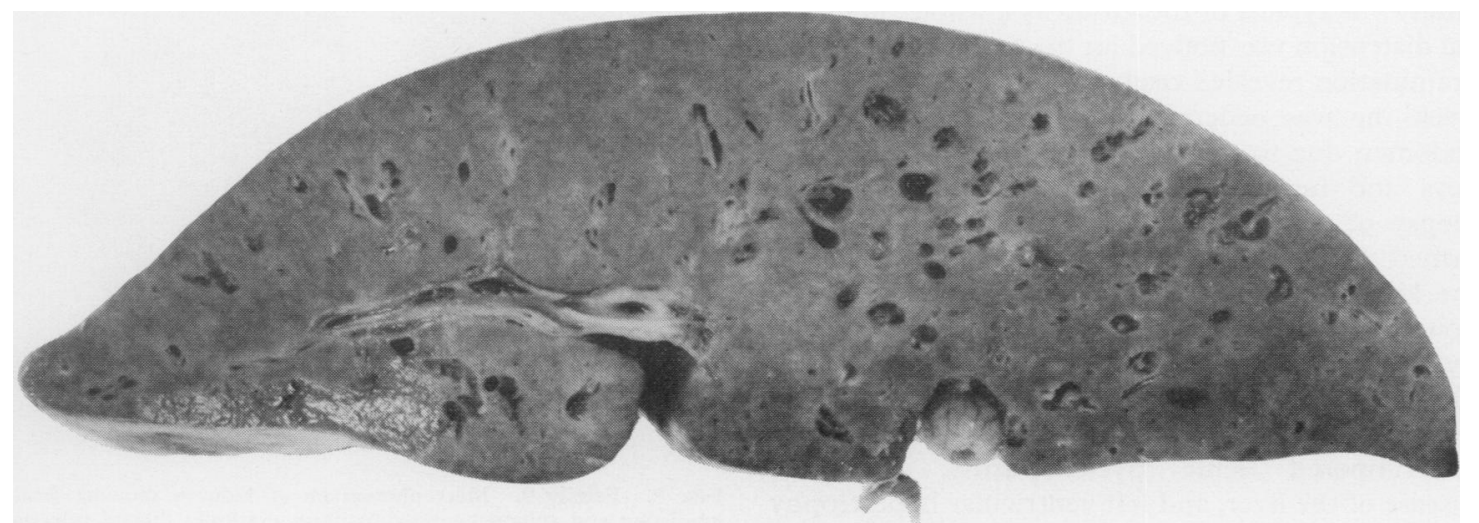

FIg. 10. Family 9. Macrophotograph of liver showing portal fibrosis and cystic bile ducts. $(\times 1$. 


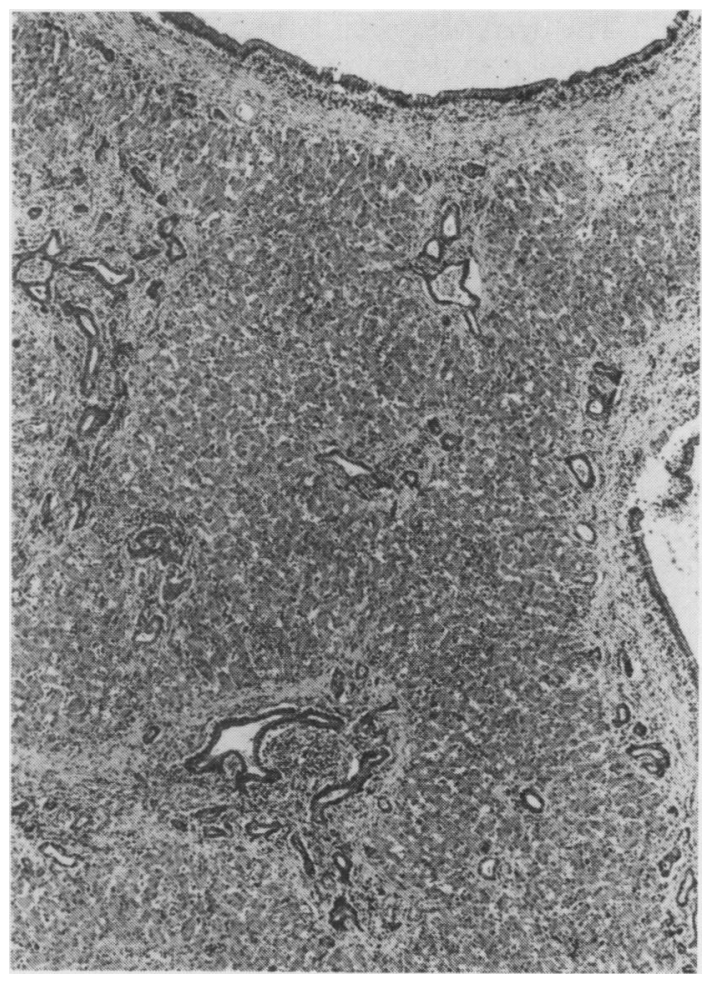

FIG. 11. Family 9. Microphotograph of liver showing ectasia and proliferation of all bile ducts, and part of wall of a large cystic duct. $(\mathbf{H} \& \mathrm{E} \times 35$.)
3. Infantile group (5 patients assessed in 5 families). All the families in this group were hospital families. Details of the sibships are given in Table VI.

TABLE VI

DETAILS OF SIBSHIPS IN INFANTILE GROUP

\begin{tabular}{|c|c|c|c|c|}
\hline \multirow{2}{*}{$\begin{array}{l}\text { Family } \\
\text { No. }\end{array}$} & \multirow{2}{*}{$\begin{array}{l}\mathbf{G} \\
\text { or } \\
\mathbf{H}\end{array}$} & \multirow{2}{*}{ Details of Sibships } & \multicolumn{2}{|c|}{$\begin{array}{c}\text { Parents' } \\
\text { Date of Birth }\end{array}$} \\
\hline & & & Mother & Father \\
\hline 12 & $\mathbf{H}$ & $F^{*}, 3.64 ; M, 4.65$ & $10 \cdot 44$ & $5 \cdot 39$ \\
\hline 13 & $\mathbf{H}$ & $\begin{array}{l}\text { M 1.51; F, } 2.54 ; F^{\circ}, 6.56, \text { d } 7 \\
\text { years } 10 \text { months; F, } 2.61\end{array}$ & 1922 & $10 \cdot 19$ \\
\hline 14 & $\mathbf{H}$ & F, 48; F, 49; $M^{\circ}, 10.57$ & $5 \cdot 27$ & $11 \cdot 25$ \\
\hline 15 & $\mathbf{H}$ & $\begin{array}{l}\mathrm{M}, 5.58 \text {; miscarriage; } \mathrm{F}, 3 \cdot 64 \text {; } \\
\text { miscarriage; } M^{*}, 8 \cdot 66\end{array}$ & $12 \cdot 33$ & 3.33 \\
\hline 16 & $\mathbf{H}$ & $\begin{array}{l}\mathrm{U}, \mathrm{SB} \text {, premature; } M, 3 \cdot 45 ; \\
\mathrm{F}, 8 \cdot 47 ; M, 3 \cdot 49 ; F^{\circ}, 6 \cdot 56 \text {, } \\
\text { d } 6 \text { years } 8 \text { months }\end{array}$ & $\underset{\text { known }}{\text { Not }}$ & $\begin{array}{c}\text { Not } \\
\text { known }\end{array}$ \\
\hline
\end{tabular}

Four of the 5 children presented between the ages of 3 and 6 months with enlargement of the liver, with or without palpable enlargement of the kidneys and/or spleen. Whether or not enlargement of the kidneys was felt at first examination, all the children were shown to have bilaterally enlarged kidneys at some stage, either on palpation, at operation, or on pyelography. The 5th child, in family 13, had not thrived well since the age of 9 months and had always suffered from polyuria and polydipsia, but was not examined until 7 years when she too was found

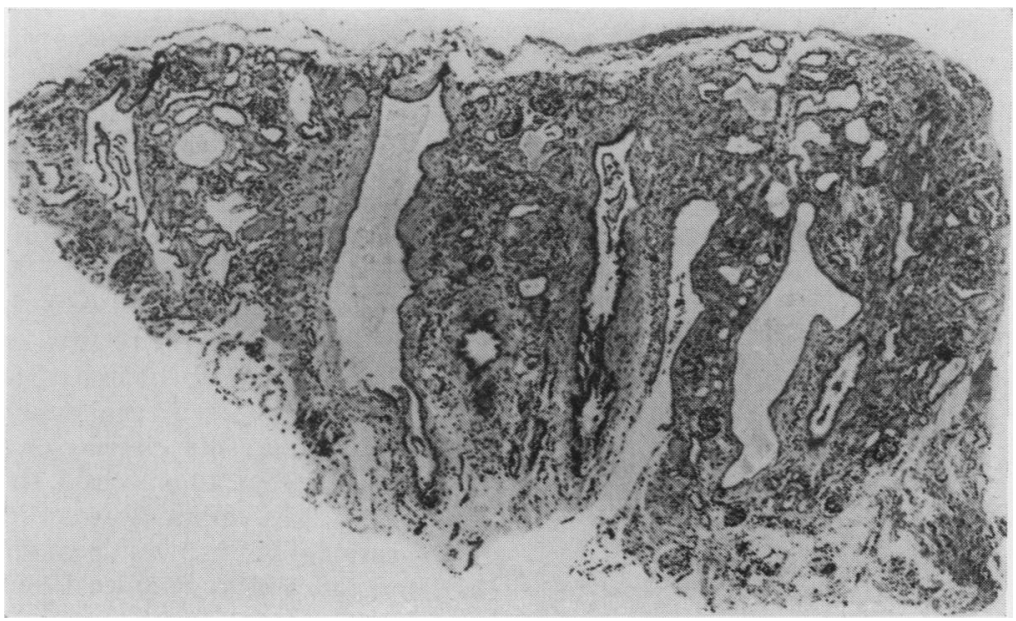

Fig. 12. Family 12. Microphotograph of minute renal biopsy showing cystic dilatation of about $25 \%$ of the renal tubules. (H \& $\mathrm{E} \times 45$.) 
to have hepatosplenomegaly and palpable kidneys. In these children the clinical picture was either of onset of chronic renal failure with raised blood urea, renal rickets and secondary hyperparathyroidism, or of increasing portal hypertensionwith oesophageal varices and haematemeses-requiring portocaval shunt. Bilateral cystic kidneys were demonstrated on intravenous pyelogram in all except the girl in family 13 in whom they were demonstrated at necropsy. At the time of study two children were dead: the girl in family 13 who died at age 7 years 10 months in uraemia, and the girl in family 16, who died at 6 years 8 months from haematemeses (following closure of a portocaval shunt performed when she was three and a half). The 3 surviving children included the boy in family 14 whose portocaval anastomosis, carried out following haematemeses at the age of 2 years, remained patent.

In this group of children, macroscopically the kidneys were enlarged, though not always markedly so, and all were cystic. In three children this was seen at operation and in one at necropsy. Histologically about a quarter of the renal tubules were

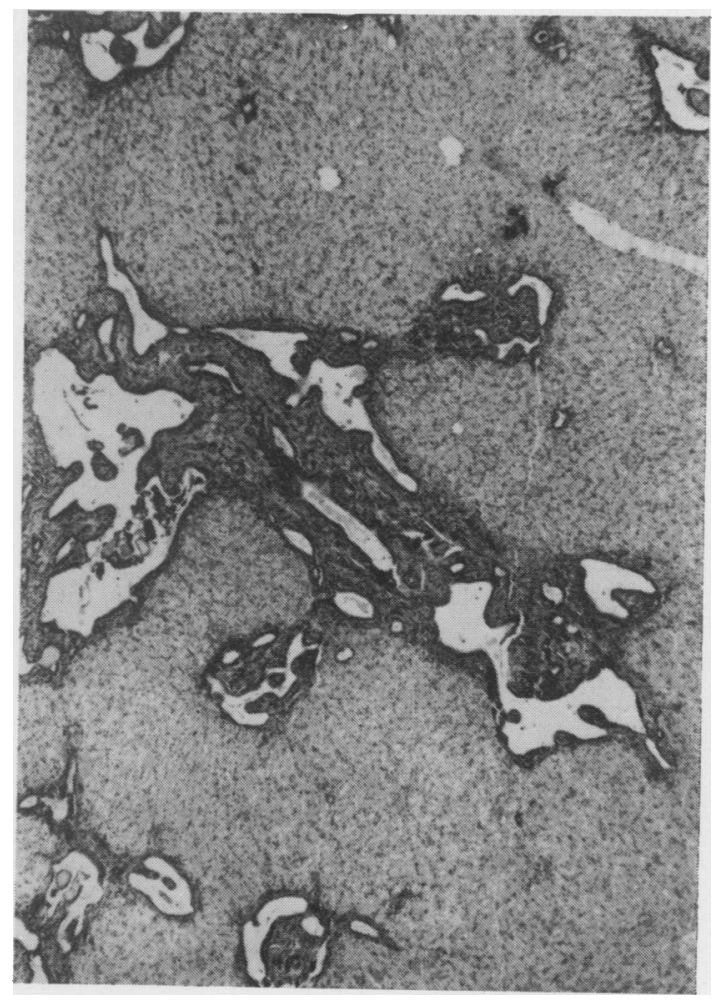

FIG. 13. Family 12. Microphotograph of liver showing ectasia of portal bile ducts and moderate periportal fibrosis. (H\& E $\times 25$.) cystically dilated in both cortex and medulla (Fig. 12). The livers were seen to be enlarged and hard -at operation in 4 and at necropsy in one child. Histologically every case showed dilatation and infolding of all the intrahepatic bile ducts and ductules available for inspection, and moderate accompanying periportal fibrosis (Fig. 13).

In this group of 5 families, in addition to the patients examined there were one affected and 10 unaffected sibs, one premature stillborn childfor whom there was no post-mortem examination -and two miscarriages. The one affected sib was the younger brother of the girl index patient in family 12. When he was two days old enlarged kidneys were palpated by the family doctor, and on admission to hospital his liver also was easily palpable. Blood urea at the age of one week was $131 \mathrm{mg} / 100 \mathrm{ml}$ and intravenous pyelogram showed 'the appearances of the infantile form of congenital polycystic disease'. This boy, like his sister, was still surviving (aged 2 years 11 months) at the time of study.

4. Fuvenile group (5 patients assessed in 4 families). All the families in this group were hospital families. Details of the sibships are given in Table VII.

TABLE VII

DETAILS OF SIBSHIPS IN JUVENILE GROUP

\begin{tabular}{|c|c|c|c|c|}
\hline \multirow[t]{2}{*}{$\begin{array}{l}\text { Family } \\
\text { No. }\end{array}$} & \multirow[t]{2}{*}{$\begin{array}{l}\mathrm{G} \\
\text { or } \\
\mathrm{H}\end{array}$} & \multirow[t]{2}{*}{ Details of Sibships } & \multicolumn{2}{|c|}{$\begin{array}{c}\text { Parents' } \\
\text { Date of Birth }\end{array}$} \\
\hline & & & Mother & Father \\
\hline 17 & $\mathrm{H}$ & $F^{\bullet}, 7 \cdot 51 ; M^{\bullet}, 7 \cdot 55$ & $2 \cdot 23$ & $9 \cdot 14$ \\
\hline 18 & $\mathrm{H}$ & $\begin{array}{l}\mathrm{M}, 6 \cdot 55, \mathrm{SB} ; F^{\cdot}, 7 \cdot 56, \mathrm{~d} 9 \\
\text { months }\end{array}$ & $7 \cdot 26$ & $6 \cdot 29$ \\
\hline 19 & $\mathbf{H}$ & $F^{\bullet}, 9 \cdot 45$, d 20 years; $M, 3.49$ & 1920 & 1921 \\
\hline 20 & $\mathbf{H}$ & $M^{\bullet}, 5 \cdot 50$ & $11 \cdot 30$ & $12 \cdot 28$ \\
\hline
\end{tabular}

Each child in this group presented with a palpably enlarged liver between the ages of one and 5 years, except for the child in family 18 whose liver enlargement was noted at 6 weeks when she was in hospital because of meningitis secondary to umbilical sepsis. Early splenic enlargement was also noted in each case but renal enlargement was variable. Typically, the clinical picture was that of portal obstruction; in one child, the girl in family17, the effect was minimal-requiring no surgical intervention-but in 3 children, the boy in family 17 and the children in families 19 and 20, portocaval shunt was required at the ages of 6,11 , and 12 respectively. The 5 th child, in family 18 died at age 9 months from renal and hepatic infection following 
umbilical sepsis, but even at this age there was splenic enlargement and early periportal fibrosis in the liver. Of the 3 children whose portal hypertension was relieved by anastomosis, the two boysin families 17 and 20 -were alive and well at the time of study but the third child-the girl in family 19-developed chronic renal failure accele-

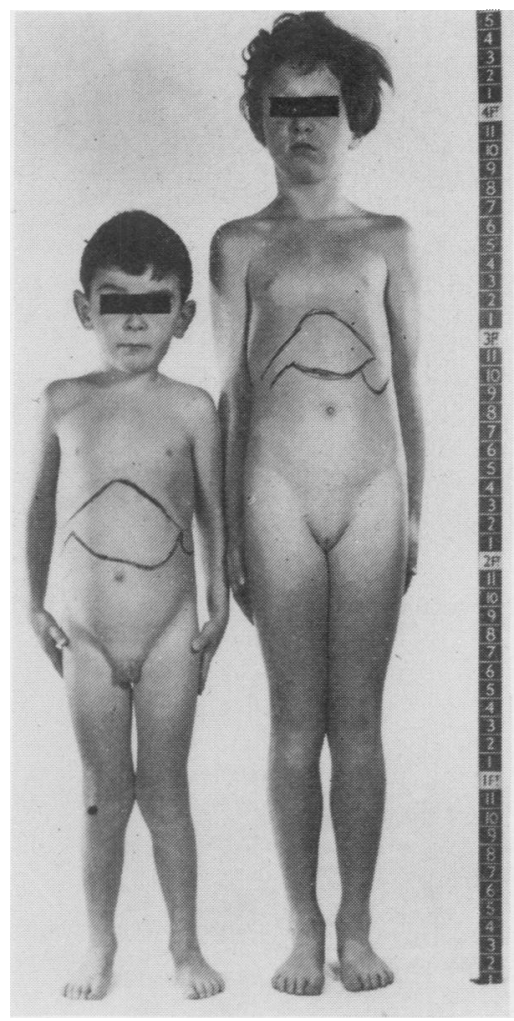

FIG. 14. Family 17. Photograph of the sibs. rated by pyelonephritis and died in uraemia just before her 21 st birthday.

The pathological findings in the children in family 17 illustrate those of the group as a whole and also illustrate the close resemblance between sibs. In this family, the girl was found to have an enlarged liver at age 5 years 6 months, and her brother at 2 years 3 months, the family doctor found this during a routine examination in each child. On referral to hospital, splenic but not renal enlargement was also found in both. Figure 14 shows these children at the ages of 8 and 4 . The boy began to have haematemeses at 4 years and a portocaval shunt was performed at 6 years. At operation the liver was seen to be large, very hard, and finely mottled; the right kidney was lobulated, normal in size, and one small cyst was seen on the surface. Biopsies were taken from both organs (Figs. 15 and 16). Percutaneous liver and kidney biopsies were taken from the girl.

Microscopically the livers of both children showed typical biliary dilatation and infoldingaffecting all the ducts and ductules-and marked biliary fibrosis, which in the boy was gross. The kidneys of both showed dilatation of about 1 in 10 or less of the tubules, uniformly distributed throughout cortex and medulla.

In the 4 sibships, in addition to the patients examined there were two unaffected sibs (one of these-in family 18-was stillborn and necropsy confirmed that the liver and kidneys were normal, death being due to tentorial tear and congenital heart disease). In family 18 , the mother had two intravenous pyelograms following passage of a renal calculus, both pyelograms were reported as being normal.

The family data for each of these 4 groups, perinatal, neonatal, infantile, and juvenile are summarized in Table VIII.

TABLE VIII

SUMMARY OF FAMILY DATA FOR CHILDHOOD TYPE OF DISEASE

\begin{tabular}{|c|c|c|c|c|c|c|c|c|c|c|c|c|c|c|c|c|c|}
\hline \multirow{3}{*}{ Group } & \multirow{3}{*}{$\begin{array}{l}\text { No. of } \\
\text { Families }\end{array}$} & \multicolumn{9}{|c|}{ Affected Children } & \multirow{2}{*}{\multicolumn{3}{|c|}{$\begin{array}{l}\text { Unaffected } \\
\text { Sibs }\end{array}$}} & \multirow{2}{*}{\multicolumn{3}{|c|}{$\begin{array}{c}\text { Total } \\
\text { Children }\end{array}$}} & \multirow{3}{*}{$\begin{array}{l}\text { Other Sibs, Status } \\
\text { unknown (perinatal } \\
\text { death without } \\
\text { necropsy) }\end{array}$} \\
\hline & & \multicolumn{3}{|c|}{$\begin{array}{c}\text { Examined } \\
\text { Histo- } \\
\text { logically }\end{array}$} & \multicolumn{3}{|c|}{$\begin{array}{c}\text { Not } \\
\text { examined } \\
\text { Histo- } \\
\text { logically }\end{array}$} & \multicolumn{3}{|c|}{ Total } & & & & & & & \\
\hline & & $\mathbf{M}$ & $\mathbf{F}$ & $\mathbf{T}$ & $\mathbf{M}$ & $\mathbf{F}$ & $\mathbf{T}$ & $\mathbf{M}$ & $\mathbf{F}$ & $\mathbf{T}$ & $\mathbf{M}$ & $\mathbf{F}$ & $\mathbf{T}$ & $\mathbf{M}$ & $\mathbf{F}$ & $\mathbf{T}$ & \\
\hline Perinatal & 6 & 3 & 6 & 9 & 一 & 一 & - & 3 & 6 & 9 & 4 & 3 & 7 & 7 & 9 & 16 & $\begin{array}{c}\text { (including } 1 \text { pair } \\
\text { of twins) }\end{array}$ \\
\hline $\begin{array}{l}\text { Neonatal } \\
\text { Infantile } \\
\text { Juvenile }\end{array}$ & $\begin{array}{l}5 \\
5 \\
4\end{array}$ & $\begin{array}{l}5 \\
2 \\
2\end{array}$ & $\begin{array}{l}1 \\
3 \\
3\end{array}$ & $\begin{array}{l}6 \\
5 \\
5\end{array}$ & 1 & $\frac{2}{-}$ & $\begin{array}{r}2 \\
1 \\
-\end{array}$ & $\begin{array}{l}5 \\
3 \\
2\end{array}$ & $\begin{array}{l}3 \\
3 \\
3\end{array}$ & $\begin{array}{l}8 \\
6 \\
5\end{array}$ & $\begin{array}{l}2 \\
4 \\
2\end{array}$ & $\begin{array}{r}5 \\
6 \\
-\end{array}$ & $\begin{array}{r}7 \\
10 \\
2\end{array}$ & $\begin{array}{l}7 \\
7 \\
4\end{array}$ & $\begin{array}{l}8 \\
9 \\
3\end{array}$ & $\begin{array}{r}15 \\
16 \\
7\end{array}$ & $\frac{1}{-}$ \\
\hline Totals & 20 & 12 & 13 & 25 & 1 & 2 & 3 & 13 & 15 & 28 & 12 & 14 & 26 & 25 & 29 & 54 & 5 \\
\hline
\end{tabular}


Fig. 15. Family 17, boy. Microphotograph of renal biopsy showing cystic dilatation of about 1 in 10 renal tubules with fairly uniform distribution. (H \& E × 35.)
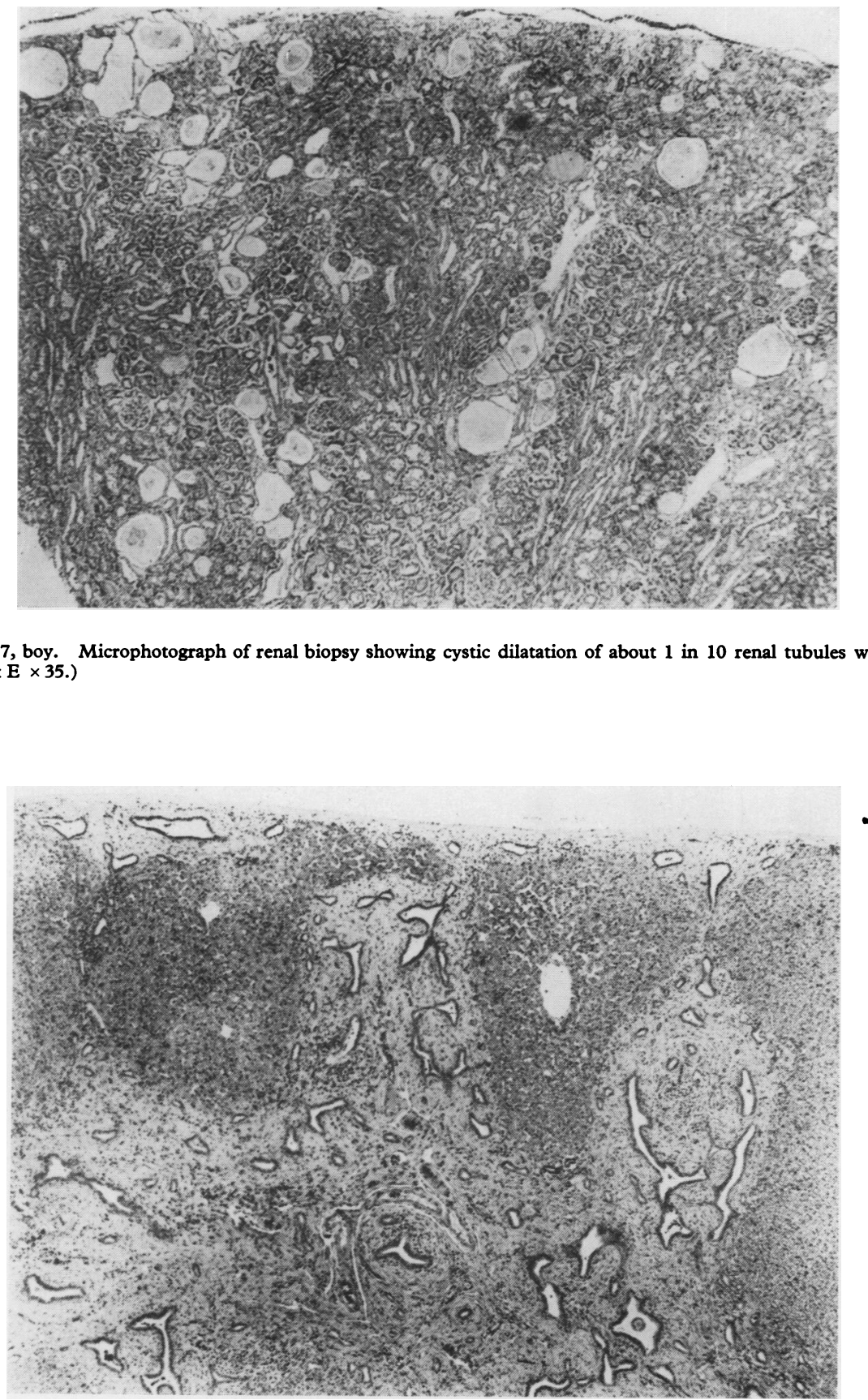

Fig. 16. Family 17, boy. Microphotograph of liver biopsy showing characteristic bile duct malformation with marked periportal fibrosis. (H\& E × 30.) 


\section{B. Adult Type of Polycystic Disease of Kidneys and Liver}

Two children in the hospital series and two children and two fetuses in the genetic clinic families proved to have a different pattern of cystic malformation of the kidneys from that already described as the Childhood type. Although initially there was some difficulty in separating these patients from the major group on histological grounds, particularly where only a small biopsy was available, characteristic differences emerged as the study proceeded. Followup of the families finally confirmed the recognition of these cases as a separate group. It became clear from this combined study that these patients had in fact the Adult dominant form of polycystic disease of the kidneys which happened to present in them at an unusually early age.

The patients and their families are described briefly in turn, each family being denoted by the first letter of the surname.

\section{Family D (genetic clinic family).}

Patient. A boy born in October 1962, birth weight $7 \mathrm{lb} 4 \mathrm{oz}$ showed satisfactory progress until, at 5 months he began to have increasing dyspnoea. On admission to hospital at 7 months the baby looked ill and wasted. Blood pressure was $150 / 105$, heart clinically enlarged, gallop rhythm; on abdominal palpation, firm irregular masses-

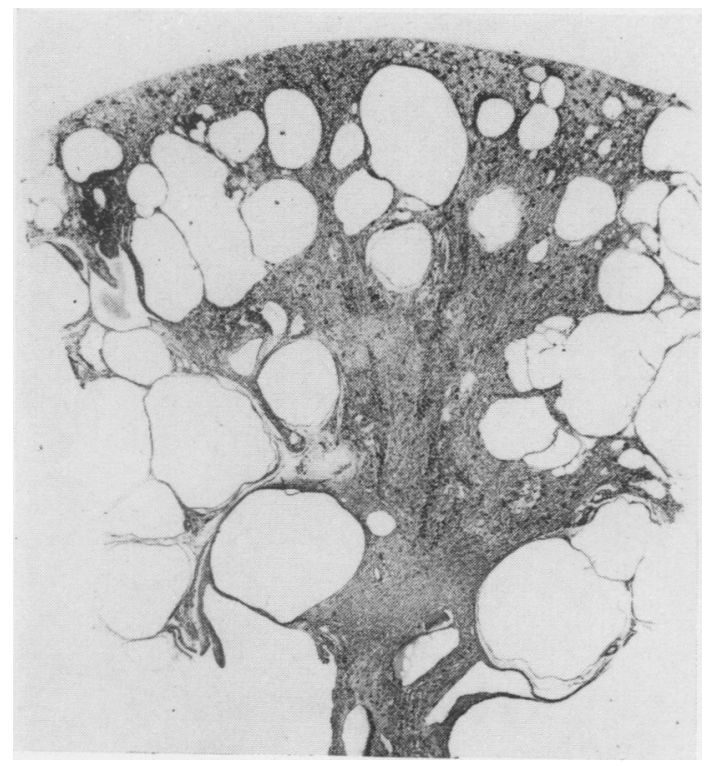

FIG. 17. Family D. Microphotograph of kidney showing irregular distribution of cysts of varying size. (H \& E $\times 4 \cdot 5$.)

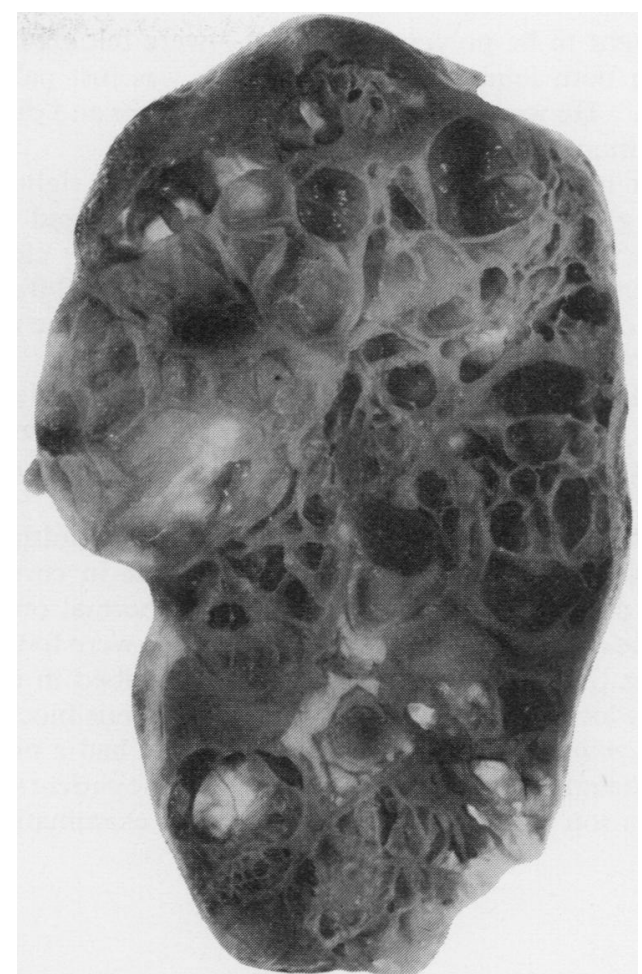

FIG. 18. Family S. Macrophotograph of kidney showing irregular distribution of cysts of varying size. $(\times 1 \cdot 1$.

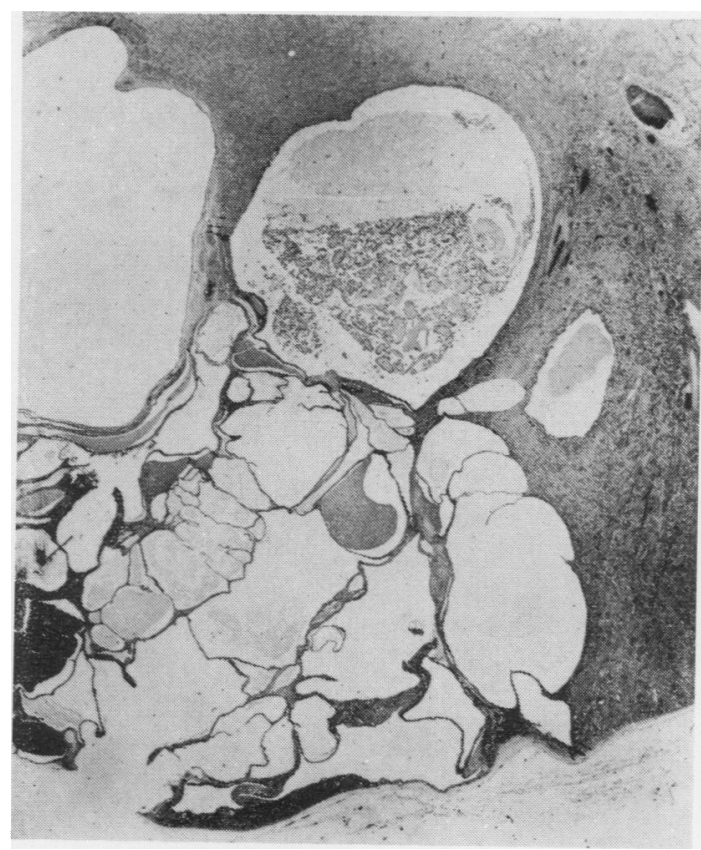

FIG. 19. Family S. Microphotograph of kidney showing focal irregular cyst formation. (H \& E $\times 4.5$. 
thought to be polycystic kidneys-were felt arising from both loins, and the liver edge was just palpable. He went into left ventricular failure and died at 7 months.

At necropsy, both kidneys (left-162 g, right$184 \mathrm{~g}$ ) were found to be considerably enlarged by many small thin-walled cysts containing clear watery fluid. Cysts varied in size from 0.1 to $2.0 \mathrm{~cm}$ and only small areas of recognizable renal tissue remained. The lower urinary tract was normal. A single thin-walled cyst was present deep in the right lobe of the liver. In the head of the pancreas was a cluster of small cysts containing clear fluid. All other organs were normal.

Microscopically, both kidneys contained multiple clusters of cystic tubules of varying size in cortex and medulla, with intervening foci of normal renal tissue (Fig. 17). In the liver, no lesions were found other than the biliary cyst already described in the right lobe, despite examination of numerous blocks.

Family. The mother had previously had a normal daughter and one miscarriage; after the patient she had a son who was clinically normal on examination

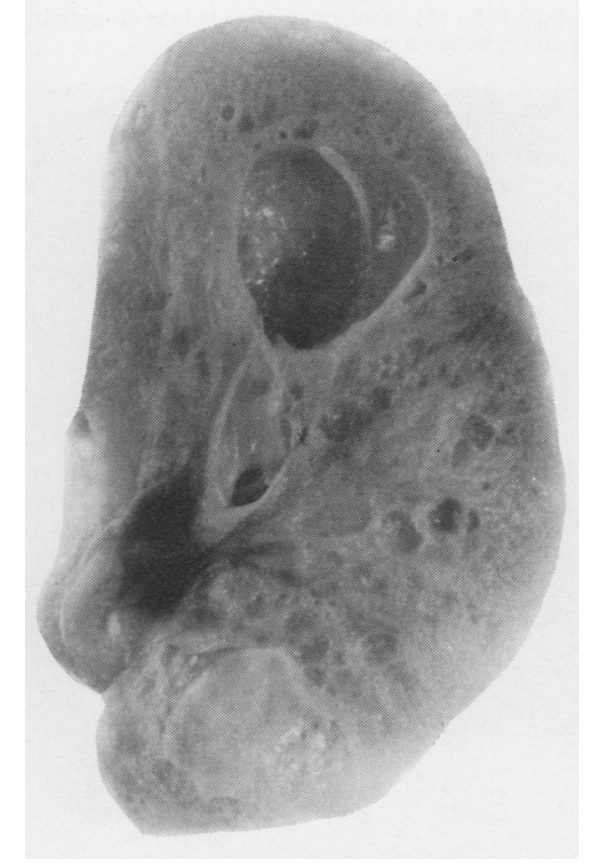

Fig. 20. Family, H, index patient. Macrophotograph of kidney showing irregular distribution of cysts of varying size. $(\times 1 \cdot 5$.) at hospital at age one. The parents and all 4 grandparents were alive and well at the time of study; none of them had had symptoms referable to the renal tract or any urological investigation.

\section{Family S (hospital case)}

Patient. A boy born October 1958 was well until the age of 6 years when he had sudden haematuria. Investigation revealed a mass in the region of the left kidney, and a left nephrectomy was performed at age 6 . The right kidney looked and felt normal. The excised kidney was greatly enlarged -weighing $628 \mathrm{~g}$ and measuring $15 \times 10 \times 8 \mathrm{~cm}$ and contained numerous cysts of greatly varying size, many of which contained pus; patches of apparently normal renal parenchyma lay between the larger cysts (Fig. 18). A section of the kidney is shown in Figure 19. Subsequent intravenous pyelogram showed the right kidney to be radiologically normal. The child has remained well.

Family. The patient had one younger brother who was well; his intravenous pyelogram in 1965 was reported normal, a slight irregularity of the left

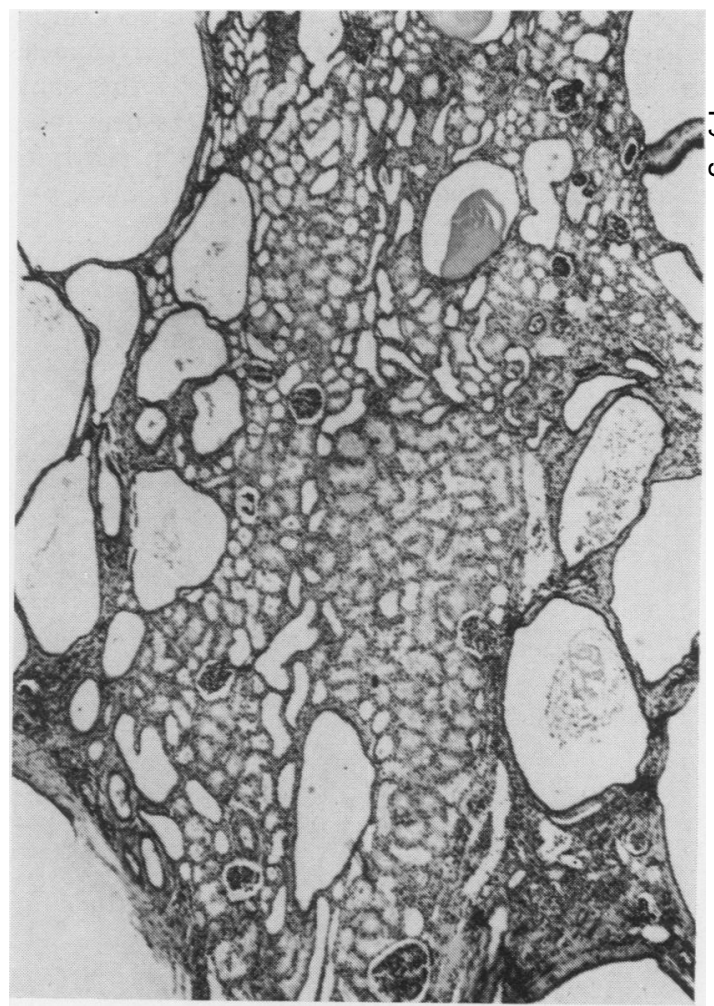

FIG. 21. Family $\mathbf{H}$, index patient. Microphotograph of kidney showing segment of renal parenchyma separating irregular tubula cysts. (H \& E $\times 27$.) 
kidney being considered of no significance. The mother was well; the father had congenital heart disease with subacute bacterial endocarditis. All 4 grandparents were alive and none was known to have had renal disease.

\section{Family $\mathbf{H}$ (hospital case)}

Patient. A girl, born August 1962. From birth she had had a 'big tummy'; was always thirsty and lived on yoghourt rather than on solid foods. At two years she was admitted to hospital with abdominal distension, pallor, and fever; intravenous pyelogram showed the left kidney to be enlarged and irregularly cystic, the right kidney being apparently normal. A left nephrectomy was performed and the excised kidney was enlarged and contained infected cysts of greatly varying size; the pelvis was normal (Fig. 20). Histologically there were irregularly distributed cystic tubules of varying size in both the cortex and medulla with intervening segments of normal renal tissue and superimposed

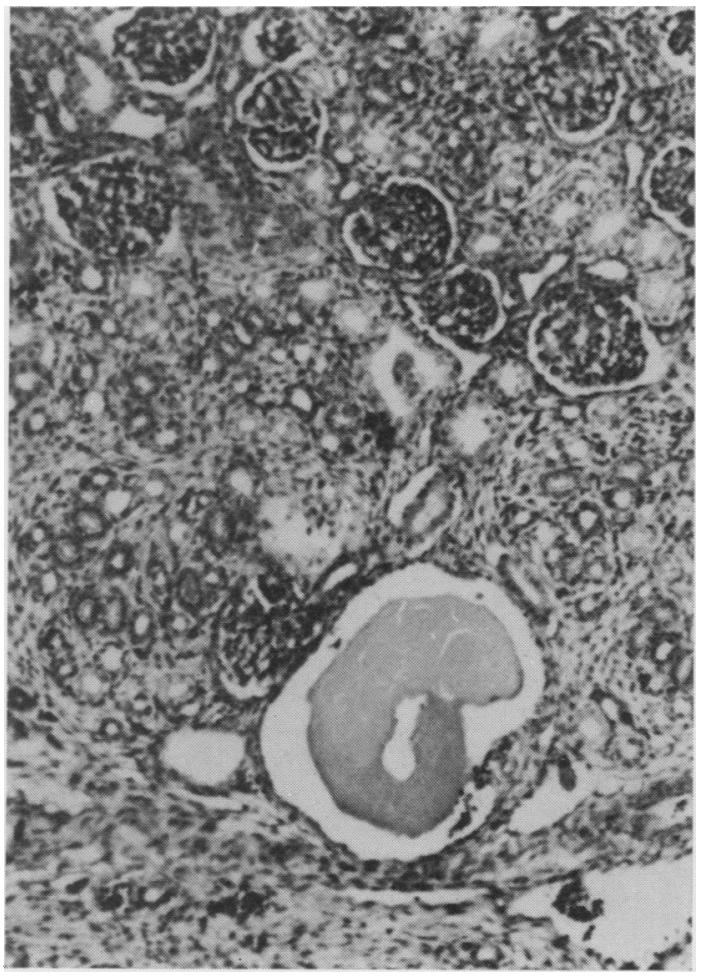

acute pyelonephritis (Fig. 21). The child improved considerably after operation. At age four, her right kidney became palpable. Intravenous pyelogram confirmed the enlargement and showed a stippled appearance throughout the renal substance

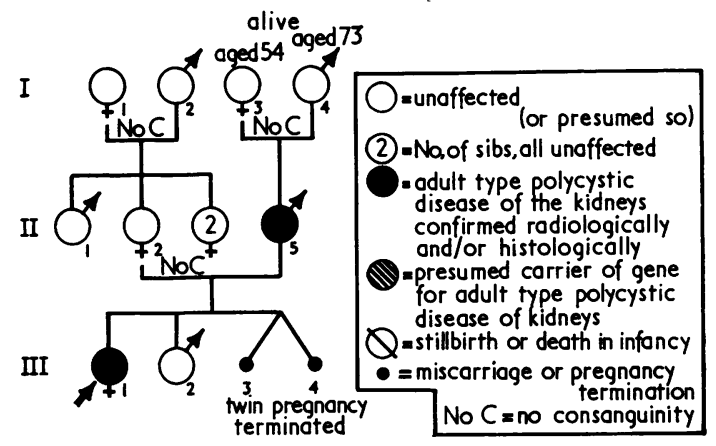

FIG. 22. Family H. Pedigree.

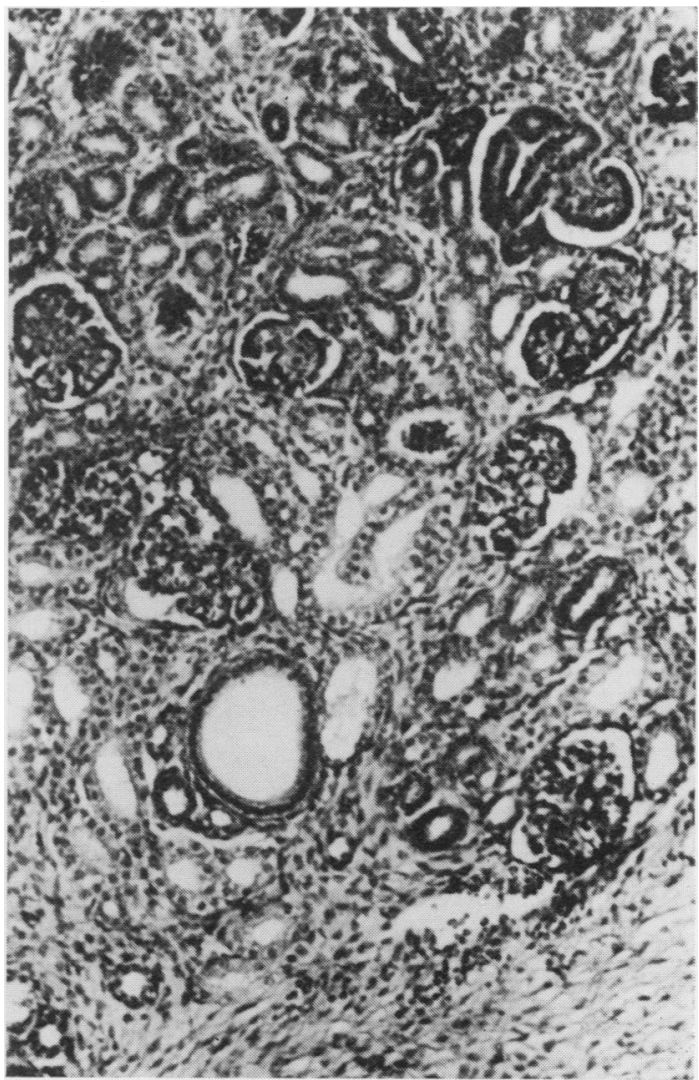

Fig. 23a and b. Family H, fetuses. Microphotographs of kidneys showing scattered cystic tubules. $(H \& E \times 50$. $)$ 
indicating cystic spaces filled with contrast medium. A needle liver biopsy taken at this time showed no histological abnormality of the one included portal tract. The child was 5 years 7 months at the time of this study; a craggy mass was palpable in the right loin, she had a blood urea in the region of $60 \mathrm{mg} / 100 \mathrm{ml}$ and variable hypertension.

Family. The family pedigree is shown in Figure 22. A younger brother was well and had a normal intravenous pyelogram. The mother was also well. The father (II.5) was well until the age of 32 when he began to have attacks of pain in the left loin. Investigation showed a palpable right kidney (though neither the left kidney nor the liver could be felt) and hypertension of 210/140 when standing and 160/110 when lying. Nephrotomogram showed enlargement of both kidneys with the typical deformities of the adult type of polycystic disease. The blood urea was only $36 \mathrm{mg} / 100 \mathrm{ml}$.

The mother then had an unplanned pregnancy and asked for a termination. This was carried out at an estimated 14 weeks after conception and twin male fetuses were found (III.3 and 4). There were no macroscopically visible cysts in the kidneys or other organs of these fetuses but microscopic examination revealed a few cortical and medullary cystic tubules in both kidneys of both fetuses (Figs. 23a and b). These were described by the pathologist who carried out the necropsies; the present authors agreed with him and found no similar lesions in the kidneys of 8 control fetuses of 14 to 19 weeks gestation. The livers of these twin fetuses were not retained for histology.

\section{Family $L$ (genetic clinic family)}

Patient. A girl, born December 1965 by Caesarean section for breech presentation. At two weeks she was found to have bilateral huge renal masses and her blood urea was $57 \mathrm{mg} / 100 \mathrm{ml}$. Intravenous pyelogram at one month showed the

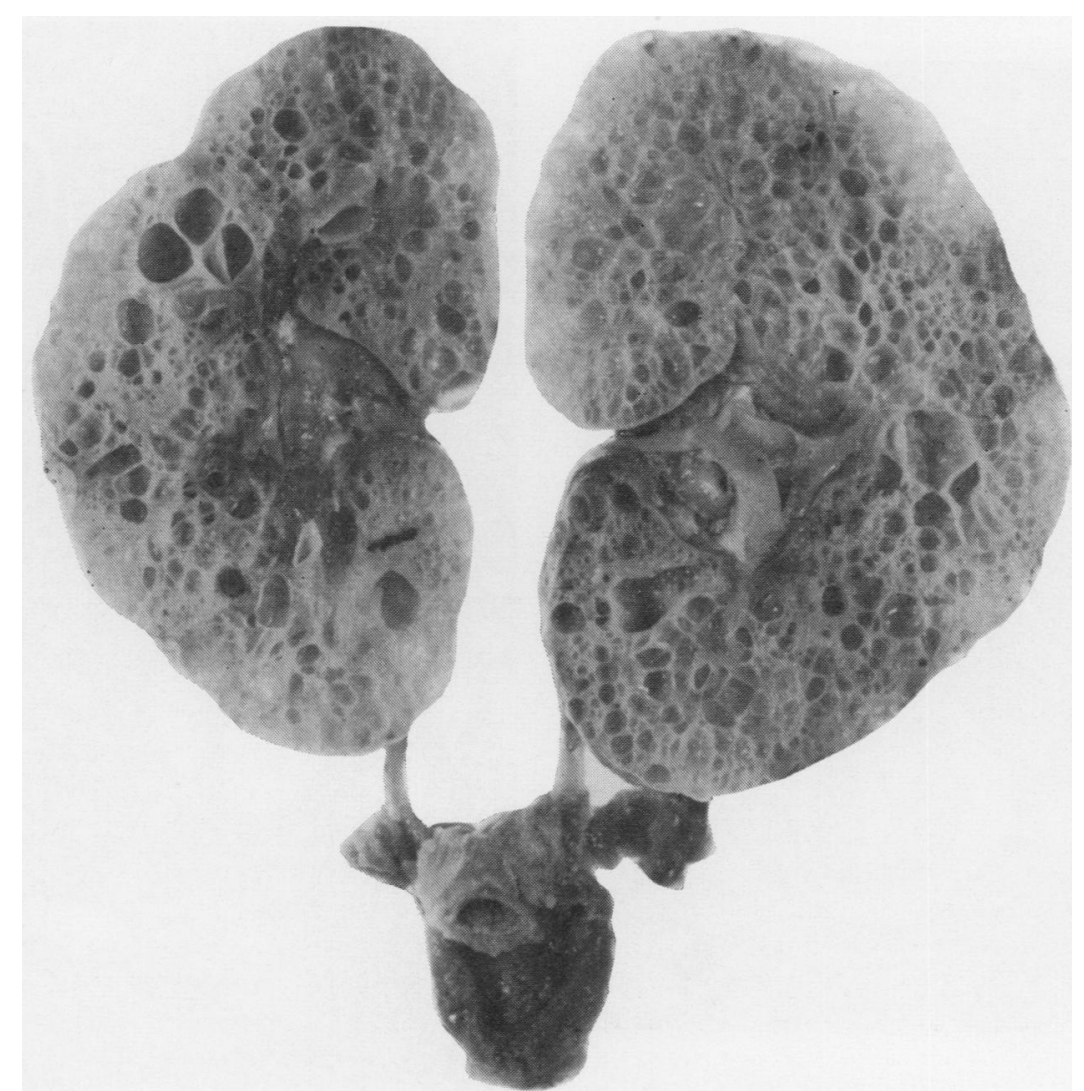
Fig. 24. Family L. Macrophotograph of cut surface of kidneys showing gross enlargement by rounded cysts of greatly varying size
(Reduced by $0 \cdot 1$. ) 


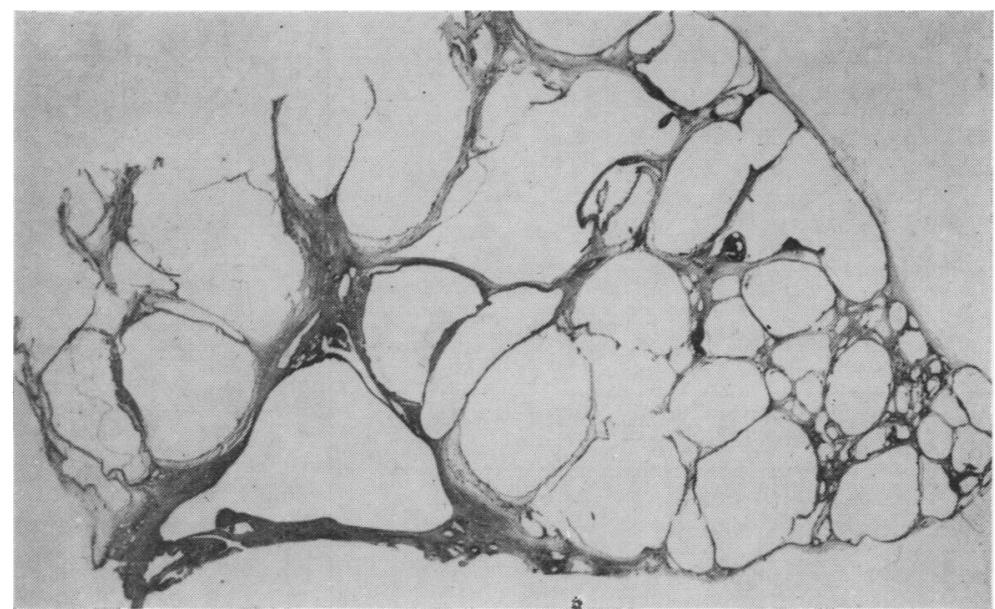

FIG. 25. Family L. Microphotograph of kidney showing gross cystic dilatation of some tubules and small foci of normal renal tissue. $(\mathrm{H} \& \mathrm{E} \times 4.5$.)

'characteristic bubble effect of polycystic disease'. Left renal biopsy at one month showed irregularly dilated tubules in cortex and medulla and foci of normal kidney tissue. The blood urea rose steadily and she died in uraemia at age 3 months.

At necropsy both kidneys were found to be grossly and uniformly enlarged by cysts of greatly varying size (Fig. 24). The lower urinary tract was

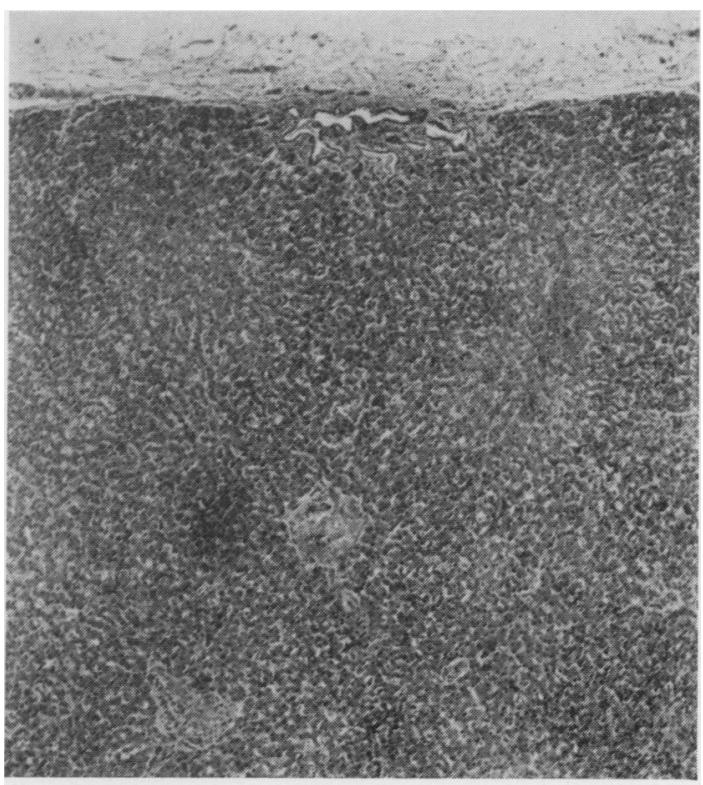

FIg. 26. Family L. Microphotograph of liver showing single bizarre infolding and dilatation of bile ducts in one portal tract. $(\mathrm{H} \& \mathrm{E} \times \mathbf{4 0}$.) normal. The liver, weight $190 \mathrm{~g}$, was congested but otherwise normal. The heart showed gross left ventricular hypertrophy. There was a right coloboma and no other abnormalities.

Microscopically the kidneys showed grossly cystic tubules of greatly varying size in both cortex and medulla and small foci of normal renal tissue (Fig. 25). Nine blocks of liver were examined: in all the sections only two portal tracts showed numerous infolded bile ducts and surrounding fibrosis, the remainder were normal. Figure 26 illustrates one of these small abnormal portal tracts in otherwise normal liver.

Family. The pedigree is shown in Figure 27.

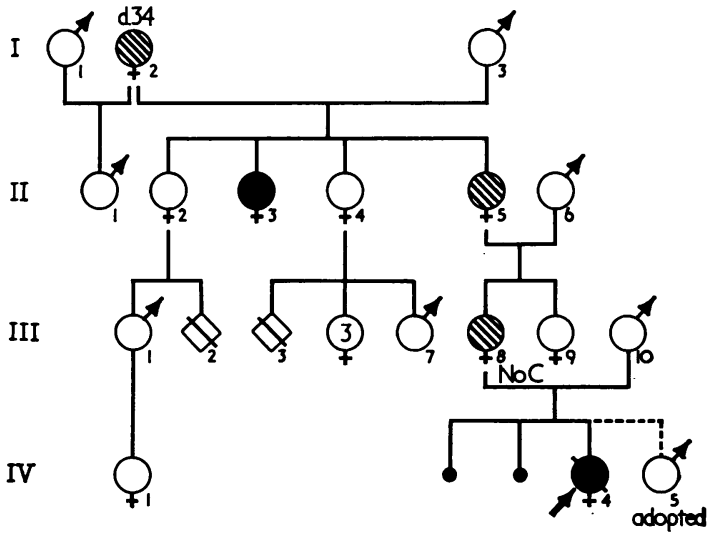

FIg. 27. Family L. Pedigree (key as for Figure 22). 
TABLE IX

FAMILY DATA FOR ADULT TYPE OF DISEASE

\begin{tabular}{|c|c|c|c|c|c|}
\hline \multirow{2}{*}{ Family } & \multirow{2}{*}{$\mathrm{G}$ or $\mathrm{H}$} & \multirow{2}{*}{ Details of Sibships } & \multicolumn{2}{|c|}{$\begin{array}{l}\text { Parents' } \\
\text { Date of Birth }\end{array}$} & \multirow{2}{*}{$\begin{array}{l}\text { Other Affected Members (diagnosis not } \\
\text { confirmed histologically) }\end{array}$} \\
\hline & & & Mother & Father & \\
\hline D & G & $\begin{array}{l}\text { F, } 10 \cdot 61 \text {; miscarriage; } M^{\circ}, 10 \cdot 62 \text {, } \\
\text { d } 7 \text { months; } M, 2.65\end{array}$ & $10 \cdot 40$ & $10 \cdot 39$ & None as far as known \\
\hline$S$ & $\mathbf{H}$ & $M^{*}, 10.58 ; M, 12.59$ & $8 \cdot 30$ & $10 \cdot 29$ & None as far as known \\
\hline $\mathrm{H}$ & $\mathrm{H}$ & $\begin{array}{c}F^{*}, 8 \cdot 62 ; M, 5 \cdot 64 ; \text { twins }\left\{\begin{array}{l}M \text { fetus } \\
M \text { fetus }\end{array}\right\} \\
\text { d } 14 \text { weeks post-conception }\end{array}$ & $9 \cdot 35$ & $9 \cdot 34$ & $\begin{array}{l}\text { Father has adult type of polycystic disease of } \\
\text { kidneys confirmed radiologically }\end{array}$ \\
\hline $\mathrm{L}$ & G & $\begin{array}{l}\text { miscarriage; miscarriage; } F^{*}, 12 \cdot 65, \\
\text { d } 3 \text { months; }(M, \text { adopted })\end{array}$ & 1.42 & $2 \cdot 42$ & $\begin{array}{l}\text { Maternal great-aunt has adult type of polycystic } \\
\text { disease of kidneys confirmed radiologically }\end{array}$ \\
\hline
\end{tabular}

The affected twins in family $\mathrm{H}$ were confirmed histologically.

The mother had two early miscarriages before the birth of the patient; after the baby's death the parents adopted a son. The father was well. The mother was also apparently well, and an intravenous pyelogram-carried out because of the finding of cystic kidneys in her daughter-was reported as normal, though the films were not available for review. The baby's maternal grandmother (II.5) had had 'kidney trouble' at 21 , since when she had attended hospital but had never been examined radiologically. The baby's great grandmother (I.2) had died at 34; the death certificate records: '1. Pyelonephritis; 2. Anasarca'. There was no necropsy. Since the death of the infant (IV.4), her great-aunt (II.3), aged 54 has been admitted to hospital with a short history of bilateral loin pain and other symptoms suggestive of a renal infection. The left kidney was found to be enlarged and tender; blood pressure was $190 / 120$ and the blood urea $33 \mathrm{mg} / 100 \mathrm{ml}$. Subsequent intravenous pyelogram showed the appearances of polycystic disease of the kidneys.

The family data for the 4 families with the Adult type of polycystic disease are shown in Table IX.

\section{Discussion}

\section{Interpretation of the Findings in the Present Series}

The first major finding of this study (see Results, section $A$ ) is that a type of cystic malformation of the kidneys occurs in children which has a characteristic pattern of tubular involvement and uniform distribution throughout both kidneys. This Childhood type of polycystic disease is always associated with an equally characteristic pattern of intrahepatic biliary malformation, accompanied by periportal fibrosis, and again the malformation is uniformly distributed throughout the organ. It is suggested that this basic pattern be designated the 'Childhood type of polycystic disease of kidneys and liver'.

The second major finding (see Results, section A) is that children affected with this type of lesion fall into the same 4 groups, whether subdivided on the basis of clinical severity or degree of renal tubular involvement. These groups are called perinatal, neonatal, infantile, and juvenile, in accordance with the characteristic age at clinical presentation (Table III). In the perinatal group there is maximal renal involvement, incompatible with survival for more than a few weeks. In the juvenile group the renal involvement is minimal and the infant survives, but with increasing age there is progressive periportal fibrosis, the cause of the morbidity in this group. The neonatal and infantile groups are intermediate between the other two.

The third major finding (Results, section B) is that the Adult dominant form of polycystic disease of the kidneys can present in infancy and early childhood but the pattern of renal and hepatic involvement differs in many respects from that of the Childhood type of disease.

The first conclusion described above may be easier to accept than the second. For example, pathologists may agree with the concept of a basic pattern of renal and hepatic malformations typically found in childhood, but be reluctant to subdivide the affected children further, preferring to view them as one continuously varying group. This might be the case were it not for the family evidence. In no instance where a family contained more than one affected child was it found that one child was classed in one group and other children from the same sibship in other groups; that is, only one clinicopathological group was represented within any one family. In those families in which slides of kidneys and liver were available from more than one 
child-families 1 and 5 in the perinatal group, family 11 in the neonatal group, and family 17 in the juvenile group-there was in fact a remarkable intrafamilial similarity in the histological features. For each of the other two families with more than one affected child-families 9 and 12-it was not possible to confirm the diagnosis histologically in the children born subsequent to the index patient. In family 9 both the affected sisters of the index patient probably had enlarged kidneys from birth; the elder girl however managed to survive to the age of 5 years, a considerably longer life span than most of the patients in this second, neonatal group, but the younger girl lived for only 3 months. In family 12 , classified as belonging to the infantile group, the younger brother of the index patient was found to have enlarged kidneys soon after birth; probably this early diagnosis was made because his doctors were already alerted to the condition as it appeared in his elder sister. His subsequent progress has resembled hers though clinically he is the more severely affected of the two children. There is therefore within-family clinical similarity of the patients in these two families, also suggesting that only one group is represented in each.

Genetic Analysis of Families with the Childhood Type of Disease. In none of the families were there affected children other than in the sibships of the patients examined histologically. In none were the parents consanguineous. The family data, summarized in Table VIII, show that the sex ratio in each group does not differ significantly from unity. On the assumption that each of the 4 groups represents a distinct genetic entity, with equal representation of the sexes and recurrence within the sibship but not elsewhere in the family, the most likely inheritance mechanism is that a separate autosomal recessive gene is responsible in each group. The data for testing this hypothesis are set out in Table X. In this Table, the hospital cases represent an unselected series and in their families the sibs are counted once for each index patient (in only one family-family 17-are there two index patients). The genetic clinic families however are highly selected since referral tends to be made after two or more affected children rather than after one. For them, sibs included in Table $\mathbf{X}$ are only those born subsequently to the parents' visit to the clinic. The proportion of affected sibs in each group is too small for tests of significance to be applied, but in no case is the proportion incompatible with the 1 in 4 ratio expected on the basis of autosomal recessive inheritance. The last column of Table $\mathrm{X}$ shows the high total of 4 stillborn babies compared with 32 live born sibs. At least one of these stillborn infants (that in family 5) was possibly affected-though in this case autolysis had proceeded too far for certain diagnosis to be madeand the 'unknown' group may well conceal further affected infants. The baby in the genetic clinic family-family 3-who died a few hours after

TABLE $\mathrm{X}$

PROPORTION OF SIBS AFFECTED WITH CHILDHOOD TYPE OF DISEASE*

\begin{tabular}{|c|c|c|c|c|c|c|}
\hline Group & Family & $\mathbf{G}$ or $\mathbf{H}$ & $\begin{array}{c}\text { Sibs } \\
\text { Affected }\end{array}$ & $\begin{array}{l}\text { Total } \\
\text { Sibs }\end{array}$ & $\begin{array}{l}\text { Proportion of } \\
\text { Sibs affected } \\
\text { in each Group }\end{array}$ & $\begin{array}{c}\text { Sibs } \\
\text { (status unknown) } \dagger\end{array}$ \\
\hline Perinatal & $\begin{array}{l}1 \\
2 \\
3 \\
4 \\
5 \\
6\end{array}$ & $\begin{array}{l}\mathbf{G} \\
\mathbf{H} \\
\mathbf{G} \\
\mathbf{H} \\
\mathbf{G} \\
\mathbf{G}\end{array}$ & $\begin{array}{l}1 \\
z \\
-\end{array}$ & $\frac{1}{\frac{1}{3}}$ & $1 / 7$ & 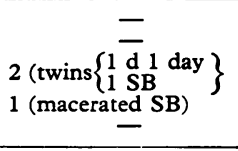 \\
\hline Neonatal & $\begin{array}{r}7 \\
8 \\
9 \\
10 \\
11 \\
\end{array}$ & $\begin{array}{l}\mathbf{G} \\
\mathbf{H} \\
\mathbf{H} \\
\mathbf{H} \\
\mathbf{G}\end{array}$ & $\frac{-}{2}$ & $\begin{array}{l}- \\
2 \\
4 \\
3 \\
1\end{array}$ & $3 / 10$ & $\bar{E}$ \\
\hline Infantile & $\begin{array}{l}12 \\
13 \\
14 \\
15 \\
16\end{array}$ & $\begin{array}{l}\mathbf{H} \\
\mathbf{H} \\
\mathbf{H} \\
\mathbf{H} \\
\mathbf{H}\end{array}$ & $\begin{array}{l}1 \\
- \\
-\end{array}$ & $\begin{array}{l}1 \\
3 \\
2 \\
2 \\
3\end{array}$ & $1 / 11$ & 1 (SB premature) \\
\hline Juvenile & $\begin{array}{l}17 \ddagger \\
18 \\
19 \\
20\end{array}$ & $\begin{array}{l}\mathbf{H} \\
\mathbf{H} \\
\mathbf{H} \\
\mathbf{H}\end{array}$ & $\frac{2}{-}$ & $\begin{array}{r}2 \\
1 \\
1 \\
\end{array}$ & $2 / 4$ & E \\
\hline
\end{tabular}

* In the genetic clinic families, only sibs born after referral to the clinic are included.

$\uparrow$ These children are not included in the total of sibs.

$¥$ Sibs are counted twice in this family: once for each index patient. 
birth, was born before referral to the clinic and is therefore not counted in the segregation analysis, but may well have been affected also.

It therefore seems reasonable to propose that children with the Childhood type of polycystic disease of kidneys and liver can be divided into four groups on clinical and pathological grounds, and that a different mutant gene is responsible in each group. These genes could perhaps be allelic, but there is no information on this.

The renal lesions in the four children considered to have the Adult type of disease resembled the childhood type of pattern to some extent but were not typical of it. The hepatic lesions were similar in form but dissimilar in that they were focal and so few that they were found only by chance. During the study, family followup of these patients revealed that in two of them-families $\mathrm{H}$ and $\mathrm{L}-$ adult relatives were affected with the typical Adult type of polycystic kidney disease. The interpretation of the renal lesions in the two children in these families then became clear: they represented an unusually severe form of dominantly inherited adult cystic disease which happened, in them to present in childhood. Review of the other two children-in families D and S-showed that they had a similar type of renal lesion. They are therefore also believed to represent the Adult dominant form of polycystic disease of the kidneys presenting in childhood.

Some other features of the Adult type of disease are illustrated in the 4 families in this series, in addition to the pattern of dominant inheritance. First, the asymmetry in time of clinical manifestation and degree of involvement which can be a feature of adult type polycystic disease (Braasch and Schacht, 1932; Oppenheimer, 1934; Dalgaard, 1957 ) is illustrated in family $\mathrm{H}$ : the girl index patient presented at 2 years with unilateral renal enlargement, the other kidney appearing normaleven on intravenous pyelogram-at that age. By age 4, after removal of one kidney, the second kidney became enlarged and detectably cystic. Also, in the boy in family 5 , the kidney which was removed showed changes typical of Adult type polycystic disease while the other kidney appeared radiologically normal. Secondly, the striking variation in severity of clinical manifestation characteristic of dominant conditions is shown in family $L$ : the mother of the severely affected infant is apparently normal clinically and radiologically, though a known transmitter. Her maternal aunt had little or no trouble until a year before she was shown radiologically to have polycystic kidneys at 54 years of age. Whether the mother develops signs or symp- toms remains to be seen. Dalgaard (1957) thinks that almost every carrier of this gene manifests it, given a life span of 80 years! Similar lack of clinical manifestation in one or other parent may account for the apparently isolated cases in families D and S; alternatively, these children may have been affected by fresh mutations. Lastly, the theory that the Adult type of polycystic disease is a congenital condition is supported by the finding of undoubted cysts in the kidneys of the twin fetuses in family $\mathrm{H}$.

Comparison of the Childhood and Adult Types. In its clinical presentation and course, as seen in the child in family $L$, the Adult type of disease may superficially resemble the Childhood type. However, the pathological and genetic differences between the two types are quite clear cut, as shown in Table XI.

Essential differences in distribution of the lesions are that in the Childhood type both kidneys are affected uniformly and symmetrically and the biliary malformations are also uniformly distributed in the liver; while in the Adult type the kidneys are not necessarily symmetrically involved, the renal cystic lesions are focal and unevenly distributed, and the hepatic lesions are also focal and, as seen in the present series, may only be identified by chance.

\section{Interpretation of Previous Reports in Relation to the Present Findings}

From the early literature it is evident that, as the Adult dominant form of polycystic disease of the kidneys was becoming established as an entity, there came-rather reluctantly-the recognition that the form usually seen in the newborn was something quite different. Earlier workers, for instance Küster (quoted in Fergusson, 1949) had clearly demonstrated two peaks in the age incidence of polycystic disease of the kidneys: one peak at or soon after birth, the other in middle life. Cairns (1925) realized that there were two different varieties: the 'adult type' and the 'congenital cystic kidney of the fetus or newborn', but he concluded that the latter were '. . . of greater value for a study of difficult labour than for a study of heredity in polycystic disease'. Marquardt (1935, 1936a, and 1936b) was probably the first to appreciate the genetic distinction between the adult and infantile types and to show that, whereas the disease is dominant in adults, the lethal form in infants usually follows a recessive pattern. The fact that he included in his recessive group examples cited from the literature which were of different aetiology-for instance Brückner's family (1869) was an obvious example of what Opitz and Howe (1969) define as 
TABLE XI

PATHOLOGICAL AND GENETIC FEATURES OF THE CHILDHOOD AND ADULT TYPES IN THE PRESENT SERIES

\begin{tabular}{|c|c|c|}
\hline & Childhood Type & Adult Type \\
\hline $\begin{array}{l}\text { Pathology } \\
\text { Kidneys }\end{array}$ & $\begin{array}{l}\text { Always bilaterally and symmetrically affected; en- } \\
\text { largement varies according to group: maximal in } \\
\text { perinatal group, minimal in juvenile group } \\
\text { Cysts fairly uniform in size; radially arranged, elon- } \\
\text { gated, and uniformly distributed throughout cortex } \\
\text { and medulla } \\
\text { Patients divisible into } 4 \text { groups on basis of number of } \\
\text { renal tubules involved } \\
\text { Pelves and ureters normal }\end{array}$ & $\begin{array}{l}\text { May be bilateral and symmetrical or apparently uni- } \\
\text { lateral } \\
\text { Cysts very irregular in size; more rounded in shape; } \\
\text { distribution focal and uneven with areas of normal } \\
\text { parenchyma also of varying size } \\
\text { Similar histology in all patients but degree of involve- } \\
\text { ment of one or both kidneys variable } \\
\text { Pelves and ureters normal }\end{array}$ \\
\hline Liver & $\begin{array}{l}\text { Usually enlarged } \\
\text { Macroscopic cysts may be present in more severe } \\
\text { forms } \\
\text { Intrahepatic biliary malformation in all portal tracts } \\
\text { Periportal fibrosis always accompanies the biliary } \\
\text { malformation; its degree varies with age }\end{array}$ & $\begin{array}{l}\text { Not enlarged } \\
\text { Macroscopic cyst present in one } \\
\text { Focal intrahepatic biliary malformation present in one }\end{array}$ \\
\hline $\begin{array}{l}\text { Other associated cystic } \\
\text { malformation }\end{array}$ & None & A cluster of pancreatic cysts present in one \\
\hline $\begin{array}{l}\text { Other associated congeni- } \\
\text { tal malformations }\end{array}$ & None consistently associated & None \\
\hline Inheritance & $\begin{array}{l}\text { Recessive; each of the four groups may be determined } \\
\text { by a different mutant gene }\end{array}$ & $\begin{array}{l}\text { Dominant; one autosomal gene with variable mani- } \\
\text { festation in the heterozygote }\end{array}$ \\
\hline
\end{tabular}

Meckel's syndrome-does not detract from the significance of his conclusion: that there are at least two clinical forms each with a different pattern of inheritance. Genetic differences of this sort, as an aid in distinguishing entities within an heterogeneous group such as that of cystic kidneys were surprisingly often ignored by contemporaries of Marquardt. Even as recently as 1959, Arey in an otherwise excellent discourse on cystic lesions of the kidney in infants and children was reluctant to concede that different modes of inheritance necessarily imply different disease entities. Fergusson (1949) however drew the distinction between the adult and neonatal forms, making the point that they never occur in the same family and appreciating the prognostic significance of the distinction. He was also concerned with latent cases of the Adult dominant type of disease in childhood, and records one of the few families in the literature in which a young child had polycystic disease of proven Adult dominant type.

It is convenient at this stage to consider further the occurrence of the Adult type of disease in childhnod since this has been a source of confusion in the literature. Steiner (1899) described two affected children, both aged 10 , members of two different families in each of which there was undoubted dominant transmission of the disease. Halbertsma (1932) described typical clinical and radiological findings in a 10-year-old girl whose father was also affected. The 2-year-old girl described by Savera (1946) who died following appendectomy, was found incidentally to have polycystic disease of the kidneys, inherited through three generations of her family. However, in all these cases, as in Fergusson's family, the diagnosis was made on clinical or radiological grounds or at operation, and it has not been possible to find a good pathological account of the findings in young children, confirmed by the family history as having the Adult dominant type of disease. The present authors were fortunate in being able to study children so affected, and to establish the pattern of severe, but focal renal, and minimal hepatic involvement of the Adult type as seen in this age group.

Published work relating to the Childhood type of polycystic disease is more difficult to unravel than that for the Adult type. The latter represents a single genetic entity with predominantly renal pathology, the hepatic malformations-even when present as multiple cysts in the adult-giving little clinical trouble (Braasch and Schacht, 1932; and others). The Childhood type of disease however is essentially bipartite-both kidneys and liver being uniformly and invariably involved in the morbid process-and probably several distinct genetic groups are represented, as suggested by the subdivision of patients with this pattern of disease into 4 separate groups. One authority who recognized the similarity of the liver lesion at different ages, and the association of this very specific biliary malformation and fibrosis in the liver with congenital cystic kidneys was MacMahon (1929). He reported 6 cases varying in age from a 7-month fetus to a 15-year-old girl (his 7th case- 'an elderly male'-the oldest patient in his series was possibly an example 
of the adult type of disease). However he did not record the essential similarity or the quantitative differences of the renal lesions in the different age groups. MacMahon's was purely a pathological study without clinical or family details, therefore he did not pick up the associated high risk to sibs. Parker (1956) and Kerr et al (1961) have noted the association of 'congenital hepatic fibrosis' with cystic kidneys in certain patients, but they do not distinguish these patients as a separate group in an otherwise heterogeneous series. Kerr and his colleagues do however note the link between 'familial' cases of congenital hepatic fibrosis and cystic kidneys. To quote from their paper: 'Comparison of familial and non-familial patients in our own and previous series reveals only one important difference: in 10 of 13 familial cases the patients had associated congenital cystic kidneys compared with 6 of the 22 non-familial cases.' Kerr later follows up this discovery with other colleagues (Kerr et al, 1962), but is still concerned only with patients who have survived infancy. The resemblance between the liver histology in patients with congenital hepatic fibrosis, when associated with the very characteristic pattern of intrahepatic biliary malformation and with cystic kidneys, on the one hand, and infants with the perinatal form of polycystic kidneys on the other hand is not mentioned. Kissane (1966) does note this resemblance.

It is difficult to find any previous suggestion in the literature that the renal lesion is qualitatively similar though quantitatively different in different age groups. One pair of workers who did appreciate this point to some extent, and suggested that there may be many gradations of polycystic disease of the kidneys was Reilly and Neuhauser (1960). They also stress the importance of associated cystic disease of the liver. However, except for the single family-reported from the clinical viewpoint by Lathrop (1959) - which they include in their series, family information is lacking, and the authors are concerned with radiographic appearances in the patients rather than with the identification of discrete entities.

Lastly, families reported in the literature in which more than one child appears to be affected by the Childhood type of disease should provide evidence for or against the suggested subdivision into 4 groups. The authors' intepretation that these groups represent different single gene determined entities is only valid if there is no overlap between groups within any given family-in other series as well as their own. They have therefore reviewed as many as possible of the recently recorded families and assigned them to one or other group on the basis of the criteria described, noting for each family whether the suggested grouping applies equally to all the affected children or whether more than one group appears to be represented in the sibship. There are obvious limitations in interpreting the findings of other workers in this way: for example, histological illustrations, however good, are no substitute for sections when judging the degree of renal involvement. Nevertheless the following rough assessment is possible.

1. Perinatal Group. Marquardt (1935) described a family with two affected infants each of whom, from the clinical description might be classifiable in the perinatal group, but there are no histological illustrations to confirm this.

Case 1 of Parker (1956) had all the features of the perinatal group; an older sib had died at 6 hours, and was thought to have had congenital cystic kidneys.

Dalgaard (1957), in Table 34 gives details of 40 propositi with the 'congenital form' of polycystic kidney; 15 were stillborn. This is obviously a heterogeneous collection of entities, but single cases which would be compatible with those in the perinatal group can be discerned. Of the instances of occurrence in sibs, none represents the perinatalo group: in two families the babies also had central nervous system malformations, and in one family they both survived for several months.

Group I of Lundin and Olow (1961) corresponds with the perinatal group of the present authors. Of the 9 cases in this group, there were 3 pairs of sibs; all the babies died within 4 hours of birth. Their report is one of the few to include family details as well as illustrations of the renal histology. They also give a genetic analysis of the families in group $\mathrm{I}$, showing that they are compatible with recessive inheritance.

Heggö and Natvig (1965a and b) describe 5 cases of 'Potter's so-called hamartomatous variety of cystic kidney' which could all be classified in the perinatal group. All the children died within 48 hours of birth, and showed exactly the same clinical and pathological features as each other and as the cases described in the present series. There are very good pathological illustrations in these papers and, as in the present authors' cases, sections from any one of these 5 infants could equally well have been taken from any of the others. The 5 infants belonged to 3 different families, and in the genetic analysis it is shown that the risk to sibs is in accordance with that expected on the basis of autosomal recessive inheritance.

Osathanondh and Potter's type I (1964a) ob- 
viously correlates with the perinatal group. They stress the uniformity of involvement in kidneys and liver, and note that this is the group in which affected sibs occur but give no actual family data.

Von Fasske (1967) described a family with three stillborn infants, each of whom showed all the features characteristic of the perinatal group.

2. Neonatal Group. Oppenheimer (1934) described a series of 60 patients of whom 59 had the adult type of polycystic kidney disease. The remaining patient was a newborn girl who died at the age of 6 months; necropsy showed bilateral polycystic kidneys and 'fatty infiltration of the liver'. Three other infants in the same sibship had died young. This family possibly accords with the neonatal group.

Dalgaard (1957), as previously mentioned, described one pair of sibs each of whom survived for some months, suggesting that they would not have been as severely affected as those in the perinatal group, and this family is a possible example of the neonatal group.

Hooper (1958) described identical twin girls both of whom died at the age of 3 months; necropsy showed bilaterally enlarged lobulated kidneys filled with minute cystic spaces. A macroscopic photograph of the kidney is shown but there is no histology.

Aurich (1967) described a family in which 5 of 8 children had bilateral polycystic kidneys and 'cystic dysplasia of the liver'. These children died at the ages of 83 days, 52 days, 10 months, 21 days, and 6 hours. From the microphotographs it is not possible to assess the number of renal tubules involved. Since one child survived to the age of 10 months it is suggested that this family might well be an example of the neonatal group. The fact that one baby died within a few hours of birth is not, of itself, an indication for inclusion in the perinatal group. This is one family in which kidney sections from all the infants would have been particularly valuable.

Becker et al (1969) described what appears to be the Childhood type of disease in three of four siblings. One of the 3 survived until 5 months, the other two died in a matter of hours after birth. Microphotographs suggest that all these babies might have belonged to the neonatal group; the two early deaths were probably attributable to hyaline membrane disease.

3. Infantile Group. Bunting (1906) described a pair of sibs, one of whom died at 11 days the other at 19 days. Both had cystic disease of the kidneys and liver, and one of them had cysts in the pancreas; there are good pathological descriptions but no illustrations. If these babies had the Childhood type of disease, they would probably both come into the infantile group because the kidneys were said to be only slightly enlarged and relatively few renal tubules were affected (mainly collecting tubules in the medulla). Factors such as prematurity no doubt contributed to their early demise.

Lightwood and Loots (1932) described a family in which 3 children had fibrosis of the liver with congenital cystic kidneys, a 4th child may also have been affected. One of these children lived to the age of 1 year and 10 months, one was alive at 4 years and one at 1 year 11 months. Details of a necropsy performed on the first child are given, but no illustrations. The findings suggest that this child may have been an example of the infantile group and the clinical findings in the other two children are also compatible with this grouping.

Kerr et al (1962) note that, in their series of patients with congenital hepatic fibrosis and cystic kidneys, a few are not easily assigned to any of their 3 groups: classical adult polycystic disease, medullary sponge kidney, and congenital hepatic fibrosis with renal lesions. Their case 15 is one such patient, and although this is not a 'familial' case, attention is drawn to this girl as a possible example of the infantile group. In fact the history and postmortem findings for this patient closely resemble those of the child in family 12 of the present series.

Cases 6 and 7 in the series of Jamaican children with congenital hepatic fibrosis described by Thorburn, Miller, and Bras (1967) are sibs, and both appear to fit into the infantile group.

The first child described in the paper by Bradford et al (1968) developed haematemesis at the age of 4 and died about a year later. Necropsy showed the typical intrahepatic biliary pattern and portal fibrosis of the Childhood type of disease; microscopically there were dilated tubules throughout the cortex and medulla of both kidneys. An older sister of this patient had died at the age of two with 'cystic disease and bad liver'. The findings in both children are compatible with those of the infantile group, as far as it is possible to judge without actually seeing the sections.

4. Juvenile Group. The three affected sibs, two of them identical twins, described in the paper by Campbell et al (1958) would probably all come within the juvenile group.

Lathrop (1959) described a family in which 4 (possibly 5) affected children in a sibship of 7 had signs of portal hypertension and cystic kidneys. At least 3 of these children appear to correspond to the 
juvenile group of the present paper. Reilly and Nuehauser (1960) describe the same family from the radiological viewpoint.

Sweetnam and Sykes' family (1961) also correlates well with the juvenile group. In this family the elder girl presented with haematemesis at age 5, requiring portocaval anastomosis at 6 ; the affected boy presented at age 2 with an enlarged abdomen, and portocaval anastomosis was carried out at 5 years. The 3 rd affected child died before the age of two from septicaemia, and necropsy showed 'the typical changes of hepatic fibrosis, and cystic kidneys with superimposed pyelonephritis. After the discovery of cystic kidneys in this 3rd child, the two surviving children-neither of whom had symptoms referable to the renal tract-were examined radiologically and the boy, who had previously been normal on $x$-ray was now found to have cystic kidneys.

Kerr and colleagues (Kerr et al, 1961) reviewed all published cases of congenital hepatic fibrosis, adding 13 new ones. Of the new cases the only 'familial' ones were the 3 children in the family reported by Sweetnam and Sykes (see above). With other colleagues, Kerr (Kerr et al, 1962) reviews 9 of the patients already described in the 1961 paper, and adds 6 new cases. Several of these new cases appear to correspond with the juvenile group; two of them, cases 13 and 14, are sibs.

Bradford et al (1968) in case 2 describe a 6-yearold girl who presented with haematemeses and hepatomegaly, and was shown on IVP to have polycystic kidneys. An illustration from the liver biopsy shows the characteristic biliary malformation and fibrosis of the childhood type of disease but there is no renal illustration. A 2-year-old brother had an enlarged liver and spleen and normal IVP. These findings are compatible with those of a family in the juvenile group, but the information that the maternal grandfather had died from cerebral vascular disease complicating polycystic disease of the kidneys (presumably Adult type) cannot be similarly explained. Professor W. D. Bradford (personal communication) supplied the further information that the finding of polycystic kidneys in the grandfather was reputedly documented at necropsy, according to the verbal report from the child's parents; also, as far as he knew, the mother of the index case had not had an intravenous pyelogram, although this had been suggested.

Van der Schoot (1955) described a family in which three sisters had hepatosplenomegaly at an early age. One sister died at 12 following haematemesis, the other two had early splenectomies and many years later were both found to have hepatic cirrhosis and cystic kidneys. It is possible that this is another example of the juvenile group but no further conclusion can be drawn in the absence of histological illustrations.

5. A Possible Group Milder than the Juvenile. A few families are recorded in which the affected members appear to have a disease similar to the Childhood type but of later onset and/or slower progression. Examples are to be found amongst the patients described by Clermont et al (1967), of which one certainly and another possibly had affected sibs, and the family described by Lorimer, McGee, and McAlpine (1967), in which 4 sibs had hepatic fibrosis (though there is no mention of cystic kidneys in any of them).

Of the reported families with more than one affected child, it appears therefore that in general there is agreement with the premise that only one group is represented within any given family. In one or two families-for example those of Aurich (1967) and Becker et al (1969)-the varying survival-times of the infants might suggest that both the perinatal and neonatal groups were represented. However, in the neonatal group the age at death can vary considerably within a given family due to infection, as demonstrated in family 9 of the present series. Examination of the renal sections (of all sibs) would be the only way to resolve this doubt.

One finding common to the published families and the present series is the lack of parental consanguinity, though Heggö and Natvig commented that the ancestors in their three families all came from the same district of western Norway. Such rare recessive disorders are usually associated with a raised incidence of parental consanguinity, but failure to demonstrate such an association may merely reflect the present low consanguinity rate in the population.

\section{Conclusions}

In children there is a characteristic pattern of cystic malformation of the renal tubules which is invariably associated with an equally characteristic malformation of the intrahepatic biliary tree, accompanied by periportal fibrosis. This 'Childhood type of polycystic disease of kidneys and liver' exists in at least 4 different forms, the essential variable being the degree of renal involvement. The most severe form-perinatal-in which about $90 \%$ or more of the renal tubules are involved corresponds with the severe form already established as an entity, variously called group I (Lundin and Olow, 1961), type I (Osathanondh and Potter, 1964a and b), and 'Potter's so called hamartomatous variety of 
cystic kidney disease' (Heggö and Natvig, 1965a and b). Infants in this group present at birth and most die in the perinatal period: none of those in the current series survived to 6 weeks. They therefore present mainly as maternity unit problems: their representation in the current series is largely - though not wholly-due to the inclusion of genetic clinic families. In the mildest of the 4 groups-juvenile- $10 \%$ or less of the renal tubules are involved, and these children present with hepatic enlargement and the effects of increasing portal fibrosis. Between the two extremes it is suggested that there are two intermediate groups: neonatal, in which about $60 \%$ of renal tubules are involved; and infantile, with about $25 \%$ of the renal tubules involved. The term 'congenital hepatic fibrosis'when accompanied by the bizarre pattern of intrahepatic biliary ectasia characteristic of the Childhood type of disease is thus applicable to all 4 groups, and is then invariably associated with some degree of renal cystic malformation.

In each group, sibs of the index patients may be affected but no one else in the family is at risk. Support for the suggested grouping is found in the family evidence, only one group being represented within any given family so far as can be judged. Segregation analysis shows that the proportion of sibs affected in each group is compatible with autosomal recessive inheritance, though the numbers are too small for tests of significance. For the future, further studies are particularly needed of families in the two intermediate groups, neonatal and infantile, with assessment of each affected child on the lines suggested.

The pathological findings in young children affected by the Adult (dominantly-inherited) type of polycystic disease are quite distinct from those of the Childhood type. The main histological differences between the two types are given in Table XI.

Finally, when counselling parents of a child with cystic kidneys of obscure aetiology, histological examination of the liver will often be of great help in deciding whether or not the Childhood type of polycystic disease is involved.

\section{Summary}

A combined clinico-pathological and genetic study was based on patients admitted to The Hospital for Sick Children, London, and families referred to the genetic counselling clinic at the same hospital. The criterion used in defining the index patients was a pattern of specific renal and hepatic malformations, later called the 'Childhood type of polycystic disease of kidneys and liver'. This pattern was found in 25 patients from 20 families. On clinicopathological criteria, these patients fell into 4 groups, named according to the age at presentation, Perinatal, Neonatal, Infantile, and Juvenile. The family evidence supported this grouping. Autosomal recessive inheritance was indicated for each group, a different mutant gene probably being involved in each.

In a further 4 patients from 4 families, the pattern of malformation was superficially similar but seen to differ in detail. Autosomal dominant inheritance, apparent in 2 of the families, supported the interpretation that these 4 patients represent the Adult type of polycystic disease of kidneys and liver presenting in childhood.

A comparison is drawn between the pathological features of the Childhood and Adult types of polycystic disease as seen in the children in this series.

The authors would have liked to name individually all colleagues who have helped in this study, but regret that the list is unacceptably long.

They express their thanks first to Dr C. O. Carter, who suggested the need for this enquiry, for his generous advice and encouragement throughout the work; also to many members of the consultant staff of The Hospital for Sick Children, Great Ormond Street for permission to visit their patients' families and quote freely from the case notes.

They are also most grateful to many colleagues in other hospitals-the pathologists for necropsy reports and histological material, and the paediatricians for information about their patients-and to the family doctors for permission to visit, and help in approaching the families in their care.

They are much indebted to Professor A. E. Claireaux, Drs D. G. Cottom and A. P. Norman, and Mr D. Innes Williams for reading the script and offering much helpful criticism.

They also thank Mr R. J. Lunnon and the staff of the Department of Medical Illustration, and $\mathrm{Mr} \mathrm{L}$. G. Spain and the technical staff of the Department of Morbid Anatomy at The Hospital for Sick Children; Miss Pamela Heath for help with the home visits ; and MrL. T. Morton, librarian, National Institute for Medical Research, for assistance with the literature.

\section{REFERENCES}

Abeshouse, B. S. and Abeshouse, G. A. (1960). Sponge kidney: a review of the literature and a report of five cases. Fournal of Urology, 84, $252-267$.

Arey, J. B. (1959). Cystic lesions of the kidney in infants and children. Fournal of Pediatrics, 54, 429-445.

Aurich, G. (1967). Uber kongenitale zystische Dysplasien. Pädiatrie und Grenzgebiete, 6, 19-34.

Becker, S. M., Finkel, J., Amboy, P., and Hyun, B. H. (1969). Polycystic kidney disease Type I. Involvement of three of four siblings with postmortem findings. Archives of Pathology, 88, 265-268.

Braasch, W. F. and Schacht, F. W. (1932). Pathologic and clinical data concerning polycystic kidney. Transactions of the American Association of Genito-Urinary Surgeons, 25, 71-87.

Bradford, W. D., Bradford, J. W., Porter, F. S., and Sidbury, J. B. Jr. (1968). Cystic disease of liver and kidney with portal hyper- 
tension. A cause of sudden unexpected hematemesis. Clinical Pediatrics, 7, 299-306.

Brückner, C. (1869). Zweimalige Entbindung derselben Frau von Missgeburten mit vergrösserten Nieren. Virchows Archiv für pathologische Anatomie und Physiologie, 46, 503-506.

Bunting, C. H. (1906). Congenital cystic kidney and liver with family tendency. Fournal of Experimental Medicine, 8, 271-288.

Cairns, H. W. B. (1925). Heredity in polycystic disease of the kidneys. Quarterly fournal of Medicine, 18, 359-392.

Campbell, G. S., Bick, H. D., Paulsen, E. P., Lober, P. H., Watson, C. J., and Varco, R. L. (1958). Bleeding esophageal varices with polycystic liver. Report of three cases. New England fournal of Medicine, 259, 904-910.

Clermont, R. J., Maillard, J. N., Benhamou, J. P., and Fauvert, R. (1967). Fibrose hépatique congénitale. Canadian Medical Association fournal, 97, 1272-1278.

Copping, G. A. (1967). Medullary sponge kidney. Its occurrence in a father and daughter. Canadian Medical Association fournal, 96, 608-611.

Cree, J. E. (for Nash, F. W.) (1969). Tuberous sclerosis with polycystic kidneys. Proceedings of the Royal Society of Medicine, 62, 327.

D'Agostino, A. N., Kernohan, J. W., and Brown, J. R. (1963). The Dandy-Walker syndrome. Fournal of Neuropathology and Experimental Neurology, 22, 450-470.

Dalgaard, O. Z. (1957). Bilateral Polycystic Disease of the Kidneys; a Follow-up of Two Hundred and Eighty-Four Patients and their Families. Munksgaard, Copenhagen.

Debré, R., Thieffry, S., Mozziconacci, P., Bargeton, E., and Ramade, J. (1952). La sclérose tubéreuse de Bourneville chez le nourrisson et le petit enfant. Archives Françaises de Pédiatrie, 9, 342-382.

Doege, T. C., Thuline, H. C., Priest, J. H., Norby, D. E., and Bryant, J. S. (1964). Studies of a family with the oral-facialdigital syndrome. New England fournal of Medicine, 271, 10731080.

Fasske, E. von (1967). Heredität angeborener Zystennieren ? Medizinische Klinik, 62, 1828-1834.

Fergusson, J. D. (1949). Observations on familial polycystic disease of the kidney. Proceedings of the Royal Society of Medicine, 42, 806-814.

Goldman, S. H., Walker, S. R., Merigan, T. C. Jr., Gardner, K. D. Jr., and Bull, J. M. C. (1966). Hereditary occurrence of cystic disease of the renal medulla. New England fournal of Medicine, 274, 984-992.

Gwinn, J. L. and Landing, B. H. (1968). Cystic diseases of the kidneys in infants and children. Radiologic Clinics of North America, 6, 191-204.

Halbertsma, L. (1932). UUber einen klinisch beobachteten Fall erblicher Cystenniere bei einen 10 jährigen Kinde. Zeitschrift für Kinderheilkunde, 52, 145-155.

Handa, S. P. and Tennant, R. (1968). Medullary cystic disease of the kidney: its occurrence in two siblings. Postgraduate Medical fournal, 44, 792-798.

Heggö, O. (1966). A microdissection study of cystic disease of the kidneys in adults. Fournal of Pathology and Bacteriology, 91, 311-315.

Heggö, O. and Natvig, J. B. (1965a). Cystic disease of the kidneys. A microdissection study. Acta Pathologica et Microbiologica Scandinavica, 63, 500-512.

Heggö, O. and Natvig, J. B. (1965b). Cystic disease of the kidneys. Autopsy report and family study. Acta Pathologica et Microbiologica Scandinavica, 64, 459-469.

Hooper, J. W. Jr. (1958). Cystic disease of the kidney in infants. Fournal of Urology, 79, 917-924.

Kerr, D. N. S., Harrison, C. V., Sherlock, S., and Walker, R. M. (1961). Congenital hepatic fibrosis. Quarterly fournal of Medicine, 30, 91-118.

Kerr, D. N. S., Warrick, C. K., and Hart-Mercer, J. (1962). A lesion resembling medullary sponge kidney in patients with congenital hepatic fibrosis. Clinical Radiology, 13, 85-91.

Kissane, J. M. Development of the kidney and congenital mal- formations. In Heptinstall, R. H. (1966). Pathology of the Kidney, 1st ed., chap. 3. Congenital malformations. Churchill, London.

Lathrop, D. B. (1959). Cystic disease of the liver and kidney. Pediatrics, 24, 215-224.

Lightwood, R. and Loots, G. H. (1932). Three cases of familial congenital cystic disease of kidney and liver. Proceedings of the Royal Society of Medicine, 25, 1230-1232.

Lorimer, A. R., McGee, J., and McAlpine, S. G. (1967). Congenital hepatic fibrosis. Postgraduate Medical fuurnal, 43, 770-773.

Lundin, P. M. and Olow, I. (1961). Polycystic kidneys in newborns, infants and children. A clinical and pathological study. Acta Paediatrica, 50, 185-200.

MacMahon, H. E. (1929). Congenital anomalies of the liver. American fournal of Pathology, 5, 499-508.

Marquardt, W. (1935). Cystenniere, Cystenleber und Cystenpankreas bei zwei Geschwistern. Dissertation, Tübingen

Marquardt, W. (1936a). Die Vererbung der congenitalen doppelseitigen Cystenniere. Der Erbarzt, 3, 69-70.

Marquardt, W. (1936b). Zur Kasuistik des familiären Auftretens der Cystennieren. Der Erbarzt, 3, 102-103.

Mongeau, J. G. and Worthen, H. G. (1967). Nephronophthisis and medullary cystic disease. American fournal of Medicine, 43, 345355.

Opitz, J. M. and Howe, J. J. (1969). The Meckel syndrome (Dysencephalia splanchnocystica, the Gruber syndrome). Birth Defects: Original Article Series, V, 2, pp. 167-179. The National Foundation-March of Dimes, New York.

Opitz, J. M., ZuRhein, G. M., Vitale, L., Shahidi, N. T., Howe, J. J., Chou, S. M., Shanklin, D. R., Sybers, H. D., Dood, A. R., and Gerritsen, T. (1969). The Zellweger syndrome (Cerebrohepato-renal Syndrome). Birth Defects: Original Article Series, V, 2, pp. 144-158. The National Foundation-March of Dimes, New York.

Oppenheimer, G. D. (1934). Polycystic disease of the kidney. Annals of Surgery, 100, 1136-1158.

Osathanondh, V. and Potter, E. L. (1964a). Pathogenesis of polycystic kidneys. Type 1 due to hyperplasia of interstitial portions of collecting tubules. Archives of Pathology, 77, 466-473.

Osathanondh, V. and Potter, E. L. (1964b). Pathogenesis of polycystic kidneys. Type 3 due to multiple abnormalities of development. Archives of Pathology, 77, 485-501.

Parker, R. G. F. (1956). Fibrosis of the liver as a congenital anomaly. Fournal of Pathology and Bacteriology, 71, 359368.

Pedreira, F. A., Marmer, E. L., and Bergstrom, W. H. (1968). Familial juvenile nephronophthisis and medullary cystic disease. Fournal of Pediatrics, 73, 77-83.

Pennisi, S. A. and Bunts, R. C. (1960). Sponge kidney. Fournal of Urology, 84, 246-251.

Reilly, B. J. and Neuhauser, E. B. D. (1960). Renal tubular ectasia in cystic disease of the kidneys and liver. American fournal of Roentgenology, 84, 546-554.

Savera, O. (1946). Zur Erbpathologie der Zystenniere. Wiener klinische Wochenschrift, 58, 422-426.

Schoot, J. B. van der (1955). Levercirrhose en cystenieren bij twee zusters. Nederlands Tijdschrift voor Geneeskunde, 99, 2579-2583.

Steiner, Dr (1899). Ueber grosscystische Degeneration der Nieren und der Leber. Deutsche medizinische Wochenschrift, 25, 677-678.

Sweetnam, W. P. and Sykes, C. G. W. (1961). Congenital fibrosis of the liver as a familial defect. Lancet, 1, 374-376.

Taylor, A. I. (1968). Autosomal trisomy syndromes: a detailed study of 27 cases of Edwards' syndrome and 27 cases of Patau's syndrome. Fournal of Medical Genetics, 5, 227-252.

Thorburn, M. J., Miller, C. G., and Bras, G. (1967). Congenital hepatic fibrosis in Jamaican children. Archives of Disease in Childhood, 42, 379-388.

Tucker, C. C., Finley, S. C., Tucker, E. S., and Finley, W. H. (1966). Oral-facial-digital syndrome, with polycystic kidneys and liver: pathological and cytogenetic studies. Fournal of Medical Genetics, 3, 145-147. 